\title{
Understanding the Interdecadal Variability of East Asian Summer Monsoon Precipitation: Joint Influence of Three Oceanic Signals
}

\author{
Zhiqi Zhang, Xuguang Sun, AND XIU-Qun Yang \\ CMA-NJU Joint Laboratory for Climate Prediction Studies, and Jiangsu Collaborative Innovation Center of Climate Change, \\ School of Atmospheric Sciences, Nanjing University, Nanjing, China
}

(Manuscript received 30 September 2017, in final form 21 March 2018)

\begin{abstract}
East Asian summer monsoon precipitation (EASMP) features complicated interdecadal variability with multiple time periods and spatial patterns. Using century-long datasets of HadISST, CRU precipitation, and the ECMWF twentieth-century reanalysis (ERA-20C), this study examines the joint influence of three oceanic interdecadal signals [i.e., Pacific decadal oscillation (PDO), Atlantic multidecadal oscillation (AMO), and Indian Ocean Basin mode (IOBM)] on the EASMP, which, however, is found not to be simply a linear combination of their individual effects. When PDO and AMO are out of phase, the same-sign SST anomalies occur in the North Pacific and North Atlantic, and a zonally orientated teleconnection wave train appears across the Eurasian mid-to-high latitudes, propagating from the North Atlantic to northern East Asia along the Asian westerly jet waveguide. Correspondingly, the interdecadal precipitation anomalies are characterized by a meridional tripole mode over eastern China. When PDO and AMO are in phase, with opposite sign SST anomalies in the North Pacific and North Atlantic, the sandwich pattern of anomalous stationary Rossby wavenumber tends to reduce the effect of the waveguide in the eastern Mediterranean region, and the teleconnection wave train from the North Atlantic travels only to western central Asia along a great circle route, causing Indian summer monsoon precipitation (ISMP) anomalies. The ISMP anomalies, in turn, interact with the teleconnection wave train induced by the PDO and AMO, leading to a meridional dipole mode of interdecadal precipitation anomalies over eastern China. Through the impact on the ISMP, the IOBM exerts significantly linear modulation on the combined impacts of PDO and AMO, especially over northern East Asia.
\end{abstract}

\section{Introduction}

Interdecadal variability of East Asian summer monsoon precipitation (EASMP) have received growing attention since the end of the 1990s (Hu 1997; Gong and Ho 2002; Zhu and Yang 2003b; Yang and Lau 2004; Kwon et al. 2007; Ding et al. 2008; Kim et al. 2010; Wu et al. 2010; Huang et al. 2011; Zhu et al. 2011; Huang et al. 2013; Jiang and Sun 2016). For example, it was found that the summer precipitation over eastern China $\left(110^{\circ}-121^{\circ} \mathrm{E}\right)$ features several important interdecadal oscillation modes: one dominant mode of near-80-yr oscillation and two secondary modes of $12-$ and 30-40-yr oscillations (Ding et al. 2008). Along with these interdecadal oscillation modes, the EASMP exhibits a complicated long-term evolution. Many previous studies revealed that the summer precipitation over eastern

Corresponding author: Xuguang Sun, xgsun@nju.edu.cn; Xiu-Qun Yang, xqyang@nju.edu.cn
China went through a remarkable transition to the so-called southern flood and northern drought (SFND) pattern around the late 1970s, which is characterized by much more precipitation over the Yangtze River valley $\left(\mathrm{YRV} ; 28^{\circ}-32^{\circ} \mathrm{N}\right)$ and much less over northern China $\left(37^{\circ}-42^{\circ} \mathrm{N}\right)$ and the lower Huang He valley $\left(35^{\circ}-38^{\circ} \mathrm{N}\right)$ (Hu 1997; Gong and Ho 2002; Zhu and Yang 2003b; Yang et al. 2005; Huang et al. 2006; Ding et al. 2008), compared to normal. Contemporaneously, the summer precipitation over southern China $\left(22^{\circ}-28^{\circ} \mathrm{N}\right)$ experienced decadal decrease around the mid-1970s but increased in the early 1990s (Kwon et al. 2007; Ding et al. 2008; Wu et al. 2010; Huang et al. 2011; Zhu et al. 2014; Jiang and Sun 2016). Additionally, a new decadal transition of the summer precipitation around the end of the 1990s was identified by recent studies (Zhu et al. 2011; Huang et al. 2013), which features increased precipitation over the lower Huang He-Huai River valley $\left(\right.$ HHRV; $\left.32^{\circ}-37^{\circ} \mathrm{N}\right)$, decreased precipitation over the south of YRV, and severe drought over northern China. 
This spatial pattern is different from the previous SFND, which implies that the interdecadal variability of the EASMP is highly complicated, with multiple time periods and spatial patterns.

Accordingly, various mechanisms are proposed to explain the interdecadal variability of the EASMP. As for the interdecadal SFND precipitation pattern, it has been attributed to the significant interdecadal weakening of the East Asian summer monsoon (EASM) around the end of 1970s (e.g., Wang 2001; Zhu and Yang 2003b), which is also closely connected with the interdecadal southwestward extension of the western Pacific subtropical high (WPSH) (Zhu and Yang 2003b; Zhou et al. 2009). Previous studies suggested that the interdecadal change of the WPSH is significantly determined by the strong interdecadal variability of sea surface temperature anomalies (SSTAs) over the northwestern Pacific and Indian Oceans, such as the negative-positive phase transition of the Pacific decadal oscillation (PDO) (Mantua et al. 1997; Zhang et al. 1997; Mantua and Hare 2002) or interdecadal Pacific oscillation (IPO) (Power et al. 1999) at the end of 1970s (Zhu and Yang 2003b; Yu et al. 2015) and tropical Indian Ocean-western Pacific warming since the late 1970s (Zhou et al. 2009). In terms of the recent decadal shift of the EASMP in the late 1990s, Zhu et al. (2015) attributed the new EASMP pattern to the anomalous meridional circulations over East Asia, which is induced by the weakened and poleward-shifted East Asian summer westerly jet, and they believed that the pattern is possibly caused by the negative PDO phase that occurred around the late 1990s. However, the EASMP patterns are different in the two negative PDO periods (pre-1970s and post-1990s), which implies a diversity of PDO impacts on the EASMP.

As one of the major components of the Asian summer monsoon system, the Indian summer monsoon (ISM) also shows distinctive interdecadal variability (Kripalani and Kulkarni 1997; Krishnamurthy and Goswami 2000), and it can have a remote impact on the variability of EASM through the atmospheric teleconnection patterns stimulated by the ISM-induced diabatic heating or cooling anomalies (Hoskins and Rodwell 1995; Ding and Wang 2005; Sun et al. 2010; Ding et al. 2011; Greatbatch et al. 2013). The interdecadal variability of ISM precipitation (ISMP) can be greatly influenced by the interdecadal variability of SSTAs in both the Indian Ocean (Kucharski et al. 2006) and the North Atlantic (Goswami et al. 2006; Lu et al. 2006; Kucharski et al. 2007, 2009). Therefore, ISMP may serve as a relay for the effects of the Indian Ocean and Atlantic Ocean on the interdecadal EASMP. On the other hand, as the dominant oceanic signal in the Atlantic Ocean, Atlantic multidecadal variability (AMV) or Atlantic multidecadal oscillation (AMO) (Kerr 2000; Enfield et al. 2001; Tokinaga et al. 2017) has significant climate impacts throughout the Northern Hemisphere (Sutton and Hodson 2005, 2007; Nigam et al. 2011; Wyatt et al. 2012; Chylek et al. 2014). Recent studies have identified that the AMO can affect East Asian climate anomalies through the interdecadal circumglobal teleconnection pattern (Wu et al. 2016a) and contributes greatly to the second leading mode of the interdecadal variability of EASM (Si and Ding 2016; Wu et al. 2016b; Li et al. 2017). In addition, recent studies also suggested that a possible influence from the AMO to IPO/PDO shifts in the late 1990s (McGregor et al. 2014; Li et al. 2016). The Indian Ocean primarily features a basinwide decadal warming or cooling pattern on the interdecadal time scale (Han et al. 2014), which is termed interdecadal Indian Ocean Basin mode (IOBM), by analogy with the ENSOinduced interannual Indian Ocean Basin mode (Yang et al. 2007). The IOBM warming can reduce the ISM but enhance the EASM, causing much less ISMP and the anomalous SFND precipitation pattern in eastern China, respectively (e.g., Kucharski et al. 2006; Sun et al. 2010; Xie et al. 2010; Greatbatch et al. 2013; Xie et al. 2016).

As major oceanic interdecadal signals, the PDO, AMO, and IOBM can have their individual impacts on the EASMP. However, in reality, they usually appear and evolve concurrently, and because of their different dominant periods (i.e., periods of 25 and $50 \mathrm{yr}$ for the PDO and a 65-80-yr period for the AMO), positive and negative phases of the PDO, AMO, and IOBM overlap with each other (Fig. 1e). Correspondingly, the combined phases of these interdecadal oceanic forcings will exert joint influence on the atmospheric circulations and the EASMP. McCabe et al. (2004) found that different phase combinations of the PDO and AMO contribute to more than half $(52 \%)$ of the temporal and spatial variability of the multidecadal drought frequency over the conterminous United States, which suggests using a "phase combination" method for investigating the interdecadal variability. Tokinaga et al. (2017) showed that a concurrent, negative-to-positive phase shift of the PDO and AMO is the major driver for the rapid earlytwentieth-century Arctic warming. As for the multidecadal EASMP anomalies, with a long-term simulation of CCSM4, Zhu et al. (2016) indicated that combined influence of the PDO and AMO can modify the East Asian subtropical westerly jet, which further induces local secondary circulations and causes interdecadal summer precipitation anomalies over eastern China. Nevertheless, because of the model biases, the simulation results cannot realistically reflect the observations. On the other hand, Si and Ding (2016) argued that the AMO can modulate the PDO effects over East Asia by 
(a) CRU TS3.23 PRE: $110^{\circ} \mathrm{E}-121^{\circ} \mathrm{E}$
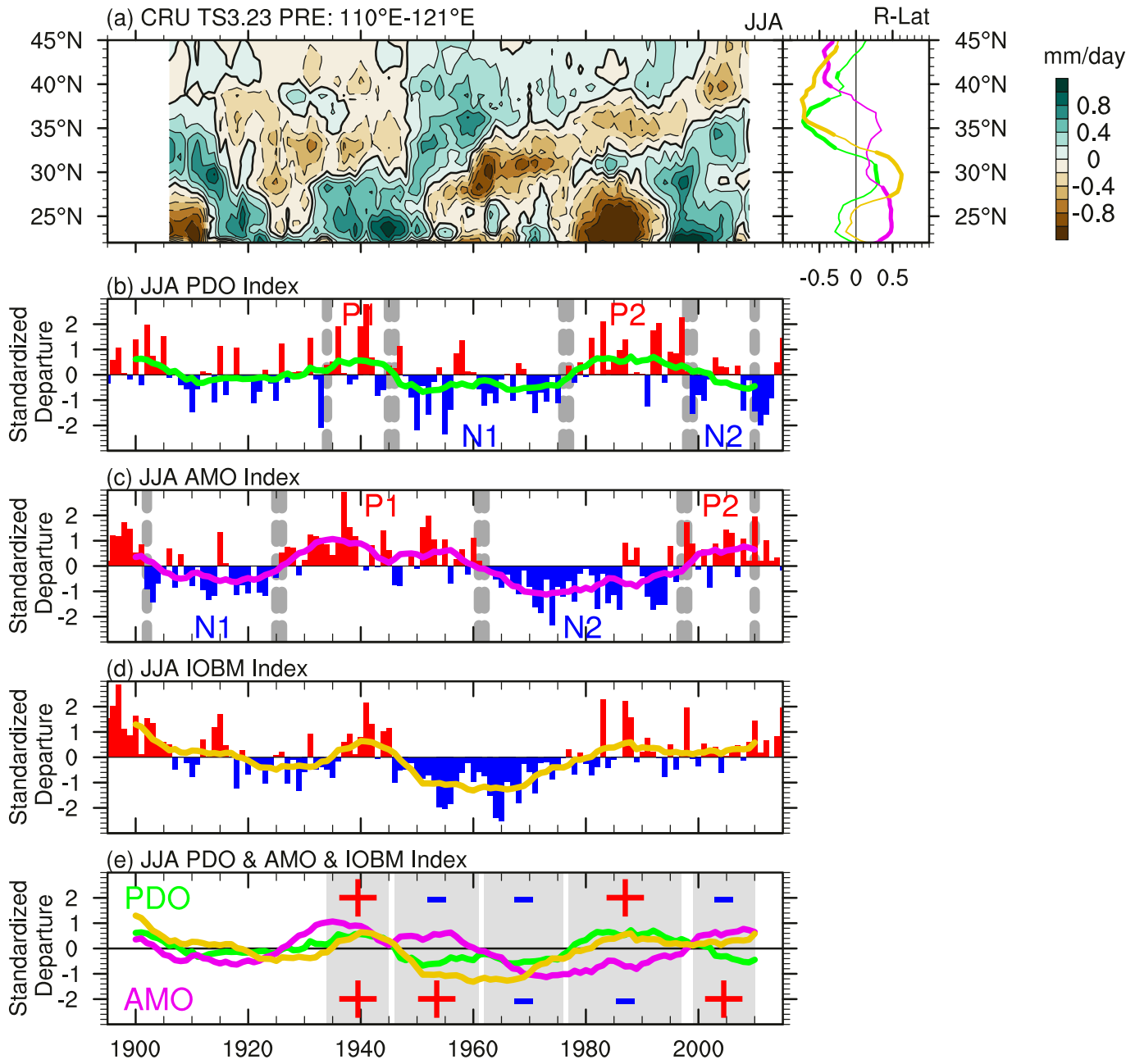

FIG. 1. (a),(left) Time-latitude cross section of 11-yr running averaged JJA precipitation anomalies $\left(\mathrm{mm} \mathrm{day}^{-1}\right)$ over eastern China $\left(110^{\circ}-121^{\circ} \mathrm{E}\right)$, accompanied by (right) their linear correlation coefficients with the 11-yr running averaged JJA oceanic indices at each latitude (PDO is green, AMO is magenta, and IOBM is gold; thickened curves indicate the $95 \%$ confidence level). Detrended and standardized indices of (b) JJA PDO, (c) AMO, and (d) IOBM (filled bars) with their 11-yr running average (colored thick lines). (e) Combined PDO and AMO phases marked with gray shading, wherein plus and minus signs indicate positive and negative phases, respectively.

altering the nature of the PDO pattern, which, to some extent, explains why the relationship of YRV-HHRV summer precipitation with the PDO varies at different periods. Wu et al. (2016b) argued that the leading mode of the interdecadal variability of the EASM is more tightly associated with the IOBM than the PDO. They speculated that the reduction in the amplitude of the leading mode after the 1960s could be associated with the concurrent change in the amplitude of the IOBM, which implies the potentially important role of the IOBM in forming the interdecadal EASMP anomalies. Obviously, the full picture about the joint influence of the PDO, AMO, and IOBM on the EASMP has not been clearly described yet, especially from the observations, not to mention the involved mechanisms.
Therefore, from the perspective of the joint influence of the oceanic signals, we reexamine the combined effects of the PDO and AMO on the interdecadal EASMP anomalies, identify the patterns of the EASMP and associated atmospheric circulation anomalies at different combined PDO and AMO phases, and illustrate the associated two types of Rossby wave trains (i.e., the Rossby waves along the Asian westerly jet waveguide and along the great circle route with the help of the ISMP). Finally, we further reveal the modulation effects of the IOBM on the combined PDO and AMO phases.

The rest of the paper is organized as follows. Section 2 describes the data and methods in this study. Section 3 demonstrates the features of interdecadal EASMP anomalies and the characteristics of the PDO, AMO, 
and IOBM and shows their linear relationships as well. Section 4 illustrates the combined impacts of the PDO and AMO on the EASMP and their associated atmospheric teleconnections. The modulation effects of the IOBM are further investigated in section 5. The final section is devoted to conclusions and discussion.

\section{Data and methods}

\section{a. Data}

The monthly SST data are from the Hadley Centre Sea Ice and Sea Surface Temperature dataset, version 1.1 (HadISST1) (Rayner et al. 2003), on a global $1^{\circ} \times 1^{\circ}$ latitude-longitude grid from January 1870 to August 2016, obtained from the website of the Met Office Hadley Centre (online at http://www.metoffice.gov.uk/hadobs/ hadisst/). HadISST1 can capture trends in global, hemispheric, and regional SST and compares well with published analyses. It is a primary choice for most atmospheric models (Rayner et al. 2003) and is also useful for studies of the large-scale signals associated with interannual to decadal climate variability (Chelton and Risien 2016).

For monthly global land precipitation, we use the high-resolution $\left(0.5^{\circ} \times 0.5^{\circ}\right.$ latitude-longitude $)$ gridded CRU time series (TS) dataset version 3.23 (Harris et al. 2014), which is produced by the Climatic Research Unit at the University of East Anglia and covers the period 1901-2014. It can be obtained from the National Centre for Atmospheric Science (NCAS) British Atmospheric Data Centre (BADC) (online at http://catalogue.ceda. ac.uk/). CRU TS datasets are calculated based on an archive of monthly observations provided by more than 4000 weather stations distributed around the world's land areas (Harris et al. 2014), and they are suitable for studies on precipitation variability over East Asia (Jiang and Sun 2016).

Monthly atmospheric reanalysis data for the twentieth century are derived by the ECMWF twentieth-century reanalysis (ERA-20C) from 1900 to 2010 at grid resolution $2^{\circ} \times 2^{\circ}$ latitude-longitude, and they are available from the ECMWF public datasets website interface (https:// www.ecmwf.int/en/research/climate-reanalysis/era-20c). ERA-20C assimilates observations of surface pressure and surface marine winds only and is produced with the ECWMF's Integrated Forecasting System (IFS) (Poli et al. 2016). The SST prescribed in ERA-20C is HadISST version 2.1.0.0 (HadISST2) (Titchner and Rayner 2014), which has major improvements on the sea ice and leaves SST basically the same as the HadISST1 (Titchner and Rayner 2014).

The study period and the climatology definition are from 1901 to 2010, and we focus only on the summer season [June-August (JJA)]. To reduce the anthropogenic influence, the linear trends are removed first for all the data and indices used in this study.

\section{b. Methods}

The PDO index is defined following Mantua et al. (1997) and Zhang et al. (1997), as the leading principal component $(\mathrm{PC})$ of the North Pacific $\left(20^{\circ}-70^{\circ} \mathrm{N}\right)$ monthly SSTAs weighted by the square root of the cosine of the latitude. The AMO index is defined following Enfield et al. (2001), as averaged North Atlantic basin SSTAs weighted by the cosine of latitude, from the equator to $60^{\circ} \mathrm{N}$ and from the east coast of North America $\left(80^{\circ} \mathrm{W}\right)$ to $0^{\circ}$ longitude. The IOBM index is defined as the cosine-of-the-latitude-weighted areaaveraged SSTAs covering the entire Indian Ocean Basin $\left(45^{\circ} \mathrm{S}-20^{\circ} \mathrm{N}, 30^{\circ}-120^{\circ} \mathrm{E}\right)$, since the SST variability in the Indian Ocean is mainly characterized by the monopolar basin-scale warming and cooling anomalies (Han et al. 2014). The indices of the PDO, AMO, and IOBM in summer from 1895 to 2015 are all linearly detrended and standardized by population standard deviations; then, the 11-yr running average is applied for filtering their long-term evolutions and determining their interdecadal phases.

To obtain the local similarity of two anomalous patterns, pattern correlation is done in a fixed, small window of $6^{\circ} \times 6^{\circ}$ latitude-longitude, which moves from grid to grid in the whole study domain, and finally a spatial pattern of pattern correlation coefficients is obtained. We termed this method "moving pattern correlation," since the small window is moving from one grid to another during the calculation of pattern correlation. Similar to the simple linear correlation, the moving pattern correlation coefficients range from -1.0 to 1.0 , and the areas with larger positive (negative) values indicate similarity (with the opposite sign) of the two patterns. Taking serial correlation into consideration, the significance of the correlation is evaluated using the two-tailed Student's $t$ test, with the effective degree of freedom $N_{e}$ calculated as

$$
N_{e}=N_{o} \frac{1-r_{1} r_{2}}{1+r_{1} r_{2}}
$$

where $N_{o}$ is the sample size, and $r_{1}$ and $r_{2}$ are the lag-1 autocorrelation coefficients of the two series (Bretherton et al. 1999). Such evaluation is also applied to the linear correlation coefficients in Table 1.

The wave activity flux (WAF) used to diagnose the energy propagation of stationary Rossby waves is calculated based on Takaya and Nakamura (2001), which has great advantages in a zonally varying climatological-mean 
TABLE 1. Linear correlation coefficients among the PDO, AMO, and IOBM indices from 1901 to 2010, before and after (indicated by an asterisk) the 11-yr running average. The first value is linear correlation coefficient $r$, the second one is corresponding critical correlation coefficient $r_{c}$ at $95 \%$ confidence level, and the boldface numbers indicate the correlation coefficient above the $95 \%$ confidence level.

\begin{tabular}{lccc}
\hline \hline$r / r_{c}$ & PDO & AMO & IOBM \\
\hline PDO & - & $-0.08 / 0.21$ & $\mathbf{0 . 3 7} / 0.21$ \\
AMO & $0.03 * / 0.83$ & - & $\mathbf{0 . 2 4 3} / 0.236$ \\
IOBM & $0.71 * / 0.86$ & $0.13 * / 0.87$ & - \\
\hline
\end{tabular}

flow. The formula for the WAF horizontal components in pressure coordinates is

$$
\mathbf{W}=\frac{1}{2|\overline{\mathbf{U}}|}\left[\begin{array}{c}
\bar{U}\left(\psi_{x}^{\prime 2}-\psi^{\prime} \psi_{x x}^{\prime}\right)+\bar{V}\left(\psi_{x}^{\prime} \psi_{y}^{\prime}-\psi^{\prime} \psi_{x y}^{\prime}\right) \\
\bar{U}\left(\psi_{x}^{\prime} \psi_{y}^{\prime}-\psi^{\prime} \psi_{x y}^{\prime}\right)+\bar{V}\left(\psi_{y}^{\prime 2}-\psi^{\prime} \psi_{y y}^{\prime}\right)
\end{array}\right]
$$

Here, $\overline{\mathbf{U}}=(\bar{U}, \bar{V})^{\mathrm{T}}$ denotes the steady zonally varying basic flow, and $\psi^{\prime}$ is the perturbation streamfunction; refer to Takaya and Nakamura (2001) for more details.

The Rossby waveguide and Rossby wave rays are also used to demonstrate the propagation of Rossby wave trains. The Rossby waveguide is a banded region where the propagation of stationary wave energy (wave activity) is confined (Hoskins and Ambrizzi 1993; Branstator 2002), and it is defined by the local maxima (larger than 7.7 in this study) of stationary Rossby wavenumber $K_{s}$ in the meridional direction, which means the Rossby waveguide is subjected to the meridional gradient of $K_{s}$. Here, $K_{s}$ is calculated following Hoskins and Ambrizzi (1993):

$$
\begin{aligned}
K_{s} & =\left(\frac{a \beta_{M}}{\bar{v}}\right)^{1 / 2} \\
& =\left\{\left[2 \Omega-\left(\frac{1}{\cos \phi} \frac{\partial}{\partial \phi}\right)^{2}\left(\cos ^{2} \phi \bar{v}\right)\right] / \bar{v}\right\}^{1 / 2} \cos \phi,
\end{aligned}
$$

where $\Omega$ is the angular rotation speed of Earth, $\phi$ is the latitude, $U$ is the westerly flow derived from the rotational wind at $300 \mathrm{hPa}, \bar{v}=U / a \cos \phi$ is the relative rotation rate of the atmosphere, and $\beta_{M}$ is $\cos \phi$ times the meridional gradient of absolute vorticity on the sphere. The $K_{s}$ depends on $U$ and is usually associated with the westerly jet (Ambrizzi et al. 1995). According to Hoskins and Karoly (1981) and Hoskins and Ambrizzi (1993), the Rossby wave rays are given by

$$
\frac{d y}{d x}=\left(\frac{K_{s}^{2}}{k^{2}}-1\right)^{1 / 2}
$$

where $K_{s}$ is the stationary wavenumber, and $k$ is the wavenumber in the $x$ direction. It indicates that the larger (smaller) the $K_{s}$, the larger (smaller) the curvature of Rossby wave rays.

\section{Interdecadal variability of EASMP and oceanic signals}

\section{a. EASMP}

Figure 1a shows the time-latitude cross section of zonally averaged summer precipitation anomalies over eastern China $\left(110^{\circ}-121^{\circ} \mathrm{E}\right)$ from 1900 to 2010 , which clearly displays the interdecadal component using an 11-yr running average. In general, the evolution of summer precipitation anomalies demonstrates two different kinds of distinct interdecadal variability north and south of the Yangtze River (around $30^{\circ} \mathrm{N}$ ). In the north, precipitation anomalies usually appear first over the YRV, and then gradually propagate northward to northern China. The initiation and propagation of anomalous wet and dry rain belts occur alternately, producing precipitation anomaly patterns like the SFND in and around the mid-1970s (e.g., Hu 1997; Gong and Ho 2002; Zhu and Yang 2003b; Yang et al. 2005; Ding et al. 2008) and northward-shifted SFND in and around the late 1990s (Zhu et al. 2011; Huang et al. 2013). However, in the south, the positive and negative precipitation anomalies happen locally at various interdecadal intervals, especially over southern China; for example, the interdecadal wet-to-dry transition in and around the mid-1970s and the interdecadal dry-to-wet transition in the early 1990s (e.g., Kwon et al. 2007; Ding et al. 2008; Wu et al. 2010; Huang et al. 2011; Zhu et al. 2014; Jiang and Sun 2016). On the other hand, precipitation anomalies in some decades are much more significant; for example, severe drought over the YRV from the end of the 1950s to the late 1970s and over southern China from the end of the 1970s to the late 1990s. Meanwhile, there are also some periods in some specific regions with no obvious interdecadal summer precipitation anomalies; for example, southern China from the early 1950s to the end of the 1970s (Fig. 1a). Since the interdecadal precipitation anomalies are likely to be related to the longterm forcing, the forcing must also be different and complicated at the interdecadal time scales. Moreover, suffering from sparse observational data prior to 1925 (Si and Ding 2016), precipitation anomalies in that period are not considered for analysis in this study.

\section{b. Oceanic signals}

Corresponding to the evolution of summer precipitation anomalies over eastern China, the linearly detrended and standardized indices of the PDO (Fig. 1b), AMO (Fig. 1c), and IOBM (Fig. 1d) and their 
11-yr running averages (Fig. 1e) are shown during the same time period.

Except for the obvious interannual variability, both the PDO and AMO feature much more remarkable interdecadal variability, and they demonstrate relatively regular interdecadal oscillations. Their positive and negative phases are marked by $\mathrm{P} 1, \mathrm{P} 2$ and $\mathrm{N} 1, \mathrm{~N} 2$, respectively, in Figs. 1b and 1c. It can also be seen that the major interdecadal period of the AMO is longer than that of the PDO. Furthermore, the PDO and AMO are nearly independent of each other, since their linear correlation coefficients are -0.08 and 0.03 before and after the 11-yr running average, respectively (Table 1). However, if we look at the phase transitions of the PDO and AMO carefully, during the study period, there are three notable phase transitions for each of the PDO and AMO: the mid-1940s, late 1970s, and late 1990s for the PDO and the mid-1920s, early 1960s, and late 1990s for the AMO. Accordingly, positive PDO phases are 193445 (P1) and 1977-98 (P2), and negative PDO phases are 1946-76 (N1) and 1999-2010 (N2); and positive AMO phases are 1926-61 (P1) and 1998-2010 (P2), and negative AMO phases are 1902-25 (N1) and 1962-97 (N2). The positive and negative phases of the PDO and the AMO are actually overlapped with each other resulting from their different periods of quasi-oscillations (Fig. 1e). Therefore, following the method of McCabe et al. (2004), positive and negative phases of the PDO and AMO are paired accordingly, and there are in total four pairs of combined PDO and AMO phases: positive PDO $(\mathrm{PDO}+) /$ negative AMO (AMO-) (1974-97), negative PDO (PDO-)/ AMO- (1962-73), PDO+/positive AMO $(\mathrm{AMO}+)(1926-45)$, and PDO-/AMO+ (1946-61 and 1998-2010) (Table 2). Because of the dataset dependency of the derived North Pacific SST variability in the early observational record, especially prior to about 1920 (Newman et al. 2016), only the PDO phases after 1925 are considered in this study.

Compared with the regular interdecadal oscillations of the PDO and AMO, the evolution of the interdecadal IOBM looks more irregular and complicated. It has a much longer time scale than the PDO and AMO, with a cooling trend from 1900 to the early 1960s but a warming trend afterward, serving as the background for the PDO and AMO (Fig. 1d). Notable transitions of cold and warm IOBM phases occur around the mid-1930s, late 1940s, and late 1970s. Though the IOBM has been in its warm phase since the 1980 s, the amplitude of positive SSTA is relatively smaller from the early 1990 s to 2010 , which may be mainly attributed to a decadal warming since the 1980s and a cooling after 1993 in the south Indian Ocean (SIO) (Zhang et al. 2017). As shown in Table 1, the IOBM has both significant and insignificant
TABLE 2. Segments of four combined PDO and AMO phases and the corresponding average values of the PDO, AMO, and IOBM indices from Fig. 1. The average for both 1946-61 and 19992010 is also shown for PDO-/AMO+.

\begin{tabular}{lcrrr}
\hline \hline Combinations & Segments & PDO & AMO & IOBM \\
\hline PDO+/AMO- & $1977-97$ & 0.65 & -0.65 & 0.20 \\
PDO-/AMO- & $1962-76$ & -0.59 & -0.91 & -1.02 \\
PDO+/AMO+ & $1934-45$ & 0.55 & 0.89 & 0.55 \\
PDO-/AMO+ & $1946-61$ & -0.35 & 0.36 & -0.92 \\
& $1999-2010$ & -0.41 & 0.64 & 0.24 \\
& Avg & -0.37 & 0.48 & -0.42 \\
\hline
\end{tabular}

positive correlations with both PDO and AMO before and after the 11-yr running average, respectively, which suggests that the IOBM is independent from the PDO and AMO on the interdecadal time scale, albeit related on the interannual time scale. Nevertheless, the interdecadal IOBM still has a close relationship with the PDO $\left(r=0.71\right.$, with $\left.r_{c}=0.86\right)$, which is mainly contributed by their similar interdecadal evolutions prior to the 1990s ( $r=0.82$, with $\left.r_{c}=0.78\right)$. Such simultaneous evolution was referred to as the "footprint" of the IPO/ PDO on the IOBM in Dong et al. (2016). However, the correlation of the IOBM and PDO is completely reversed to largely negative after the mid-1990s $(r=-0.66$, with $\left.r_{c}=0.68\right)$, especially in the recent decade, when the PDO is in negative phase and the Indian Ocean is in progressive warming (Fig. 1e), indicating the partially dependent relationship of the IOBM and PDO (Han et al. 2014).

\section{c. Linear relationships of EASMP and oceanic signals}

Based on the 11-yr running averaged data, linear correlations are calculated between the indices of PDO, AMO, and IOBM and the zonally averaged summer precipitation anomalies over eastern China, and they are shown as latitudinal profiles on the right side of the time-latitude section plot in Fig. 1a. Correlated with the PDO, significant negative and positive correlation coefficients of precipitation anomalies over northern China $\left(35^{\circ}-44^{\circ} \mathrm{N}\right.$; HHRV and northern China) and the YRV, respectively, form a meridional dipole correlation pattern like the SFND, which is also consistent with the relationship of the PDO and the SFND pattern revealed by previous studies (e.g., Zhu and Yang 2003b). As for the AMO, the significant positive correlations of precipitation anomalies appear over southern China, coinciding with that in Wang et al. (2009), and significant negative correlations lie over northernmost northern China $\left(40^{\circ}-45^{\circ} \mathrm{N}\right)$. Similar to the PDO, the correlated precipitation anomalies with the IOBM also display a significant SFND pattern, wherein the northern China 

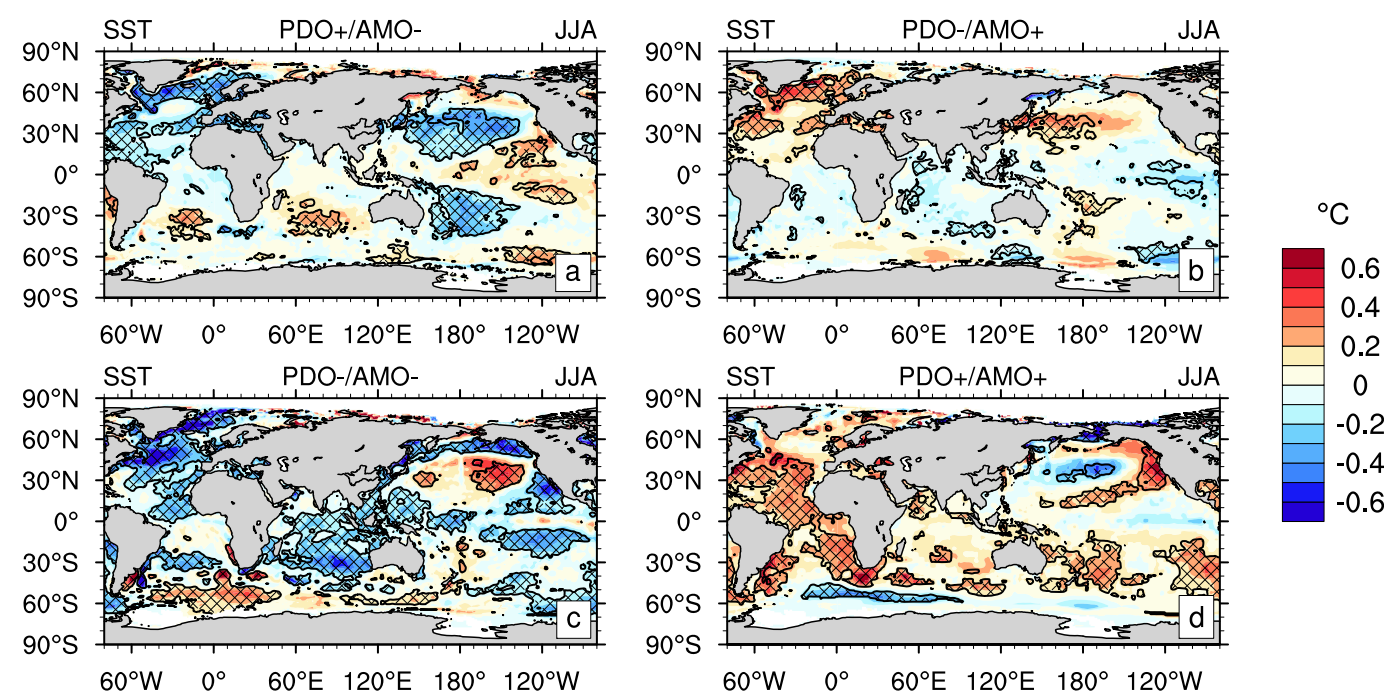

FIG. 2. Composited JJA SSTAs (shading, ${ }^{\circ} \mathrm{C}$ ) in four combined PDO and AMO phases: (a) PDO+/AMO-, (b) $\mathrm{PDO}-/ \mathrm{AMO}+$, (c) $\mathrm{PDO}-/ \mathrm{AMO}-$, and (d) $\mathrm{PDO}+/ \mathrm{AMO}+$. The $90 \%$ and $95 \%$ confidence levels are denoted by thick black contour lines and cross hatching, respectively.

negative precipitation anomalies associated with the IOBM warming may be linked to the negative relationship between ISM and IOBM SSTAs (Kucharski et al. 2006). As we will show in section 5, the ISM is reduced by the IOBM warming through the decreased land-sea thermal contrast, and in turn, it can cause less precipitation over northern China through the atmospheric teleconnection wave trains, and vice versa (Kucharski et al. 2006; Sun et al. 2010; Greatbatch et al. 2013). Overall, over both northern China and the YRV, PDO, AMO, and IOBM have consistent influences on summer precipitation anomalies, albeit affecting different areas, but over the HHRV and southern China, their effects are inconsistent among each other. Therefore, for some specific regions, the precipitation anomalies have significant but different relationships with PDO, AMO, and IOBM separately.

\section{Combined impacts of PDO and AMO}

\section{a. Global SSTA patterns}

Based on the four pairs of combined PDO and AMO phases (Table 2), summer global SSTAs are composited accordingly and shown in Fig. 2. In the PDO+/AMOphase (Fig. 2a), both the North Pacific and North Atlantic are covered by significant cooling SSTAs, whereas significant warming SSTAs with smaller amplitude appear along the North American Pacific coast and in the tropical mideastern Pacific. The composite SSTA pattern in the $\mathrm{PDO}-/ \mathrm{AMO}+$ phase is nearly reversed, compared to that in the PDO+/AMO- phase (Fig. 2b).
In the PDO-/AMO - phase (Fig. 2c), significant positive SSTAs occur in the central-western North Pacific, surrounded by negative SSTAs in the North Pacific including the northwestern North Pacific, whereas significant negative SSTAs dominate the whole North Atlantic. At the same time, IOBM cooling is also remarkable, which is probably due to the consistent relationships of the PDO and AMO with the IOBM (Table 1). Similarly, the composite SSTA pattern is almost the opposite in the PDO+/AMO+ phase for all three ocean basins (Fig. 2d).

Therefore, when PDO and AMO are out of phase (PDO +/AMO - and PDO-/AMO + in Figs. 2a and 2b, respectively), the same-sign composite SSTAs dominate the Northern Hemispheric oceans (North Pacific and North Atlantic), and the Indian Ocean SSTAs are very weak. When the PDO and AMO are in phase (PDO-/ $\mathrm{AMO}-$ and $\mathrm{PDO}+/ \mathrm{AMO}+$ in Figs. $2 \mathrm{c}$ and $2 \mathrm{~d}$, respectively), signs of composite SSTAs are opposite between the central North Pacific and the North Atlantic. Moreover, there are also significant SSTAs in the Indian Ocean, with the same sign as those in North Atlantic. Thus, according to the different combined PDO and AMO phases, the global SSTA patterns seem to be the simply linear superpositions of the PDO and AMO. However, there still exist some asymmetries among them. For instance, in different AMO phases, same PDO phases show inconsistent SSTA distributions in the North Pacific and Indian Oceans (Fig. 2a vs Fig. 2d and Fig. 2c vs Fig. 2b), which cannot be discerned and presented by linear regression on the PDO index ( $\mathrm{Si}$ and Ding 2016; Wu et al. 2016b). 

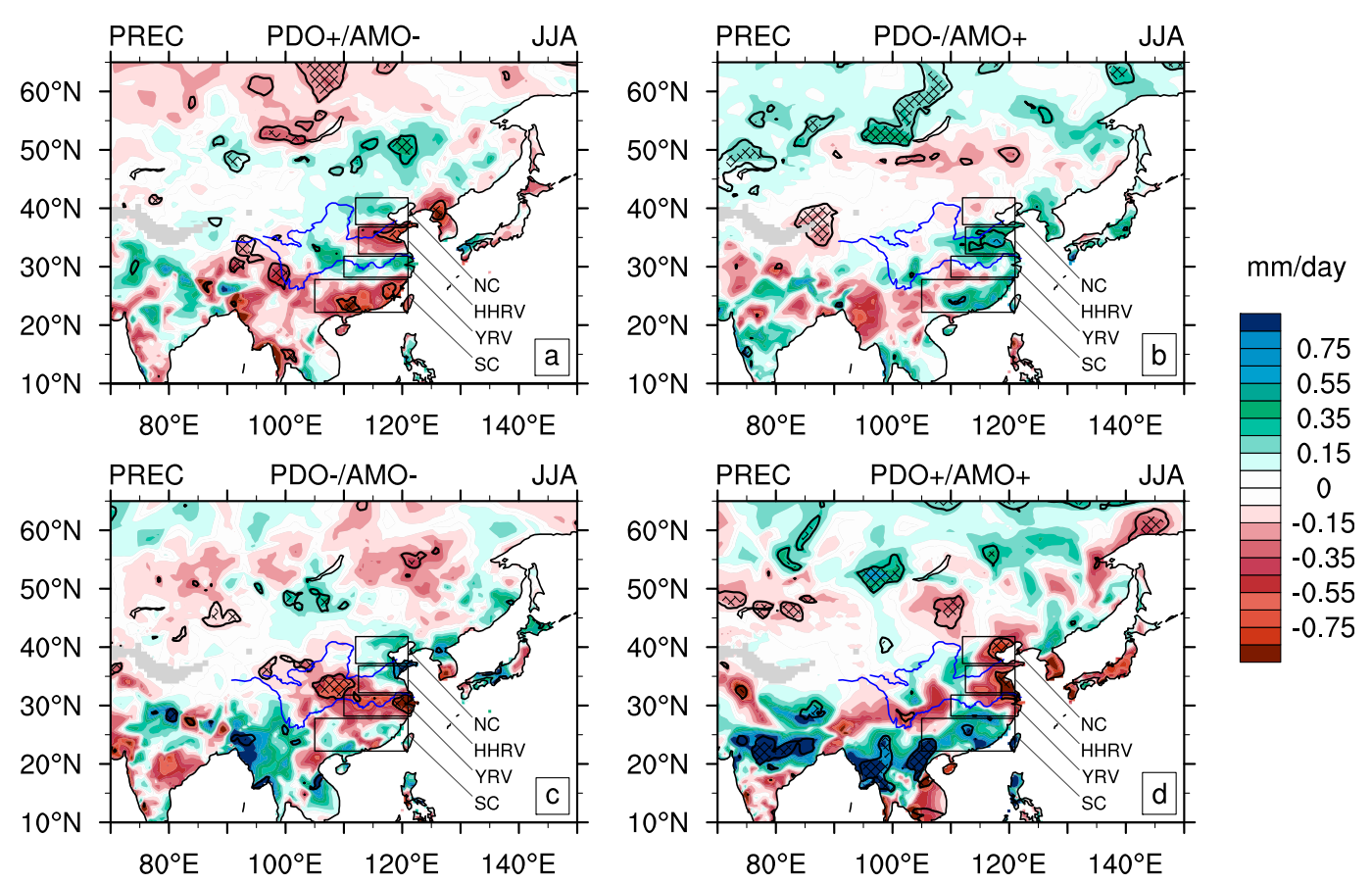

FIG. 3. As in Fig. 2, but for JJA precipitation anomalies over East Asia (shading, $\mathrm{mm} \mathrm{day}^{-1}$ ). The rectangles indicate the subregions over eastern China: northern China $\left(\mathrm{NC} ; 37^{\circ}-42^{\circ} \mathrm{N}\right)$, HHRV $\left(32^{\circ}-37^{\circ} \mathrm{N}\right)$, YRV $\left(28^{\circ}-32^{\circ} \mathrm{N}\right)$, and southern China $\left(\mathrm{SC} ; 22^{\circ}-28^{\circ} \mathrm{N}\right)$, from north to south. The $90 \%$ and $95 \%$ confidence levels are denoted by thick black contour lines and cross hatching, respectively.

\section{b. EASMP anomalies}

Corresponding to the composite SSTAs, composite precipitation anomalies are demonstrated in Fig. 3 for the different combined PDO and AMO phases. In the $\mathrm{PDO}+/ \mathrm{AMO}-$ phase (Fig. 3a), along the coast of East Asia, there is an obvious meridional precipitation teleconnection embedded with a meridional tripole mode over eastern China; that is, less precipitation in the HHRV and southern China and more precipitation in the YRV. By contrast, in the PDO-/AMO+ phase (Fig. 3b), the anomalous precipitation pattern is almost reversed, similar to the SSTA relationship between the $\mathrm{PDO}+/ \mathrm{AMO}-$ and $\mathrm{PDO}-/ \mathrm{AMO}+$ phases. In the PDO-/AMO - phase (Fig. 3c), there is a clear meridional dipole mode over eastern China: that is, reversed SFND (less precipitation in the YRV and more precipitation in the HHRV and northern China). A precipitation teleconnection also appears from India to northern China along the northwest of Indochina and central China, implying the impacts of ISM (Sun et al. 2010; Greatbatch et al. 2013). Generally, precipitation anomalies in the $\mathrm{PDO}+/ \mathrm{AMO}+$ phase have nearly opposite distribution patterns to those in the PDO-/ AMO - phase; however, some exceptions still exist in middle and southern East Asia and South Asia (Fig. 3d). For example, in the $\mathrm{PDO}+/ \mathrm{AMO}+$ phase, significantly fewer precipitation anomalies occur over the HHRV and YRV, but many more are over southern China, the middle of Indochina, and central India, located near the interfaces of positive and negative anomaly centers in the PDO-/AMO - phase. Such exceptions may be related to the feedback of the ISMP and the modulation effects of significant IOBM SSTAs when the PDO and AMO are in phase; specifically, negative ISMP anomalies in the PDO-/AMO - phase may be partly canceled out by the cold IOBM (Kucharski et al. 2006; Wang et al. 2009; see also section 5).

The phase-combined PDO and AMO can depict the observational long-term evolutions of precipitation anomalies over eastern China very well (Figs. 3 and 1a). Specifically, the SFND pattern around the 1940s corresponds to the $\mathrm{PDO}+/ \mathrm{AMO}+$ phase; the $\mathrm{PDO}-/$ $\mathrm{AMO}+$ phase is responsible for the significant positive precipitation anomalies over the HHRV in around the late 1950s and early 2000s; striking drought over the YRV around the 1970s coincides well with the PDO-/ AMO - phase; and finally, corresponding to the $\mathrm{PDO}+1$ AMO - phase, the period from the late 1970s to late 1990s experiences significantly less precipitation over the HHRV and southern China. Note that the single oceanic signal is not enough to illustrate the interdecadal precipitation anomalies. For instance, linear correlation shows a closely positive relationship between the PDO 

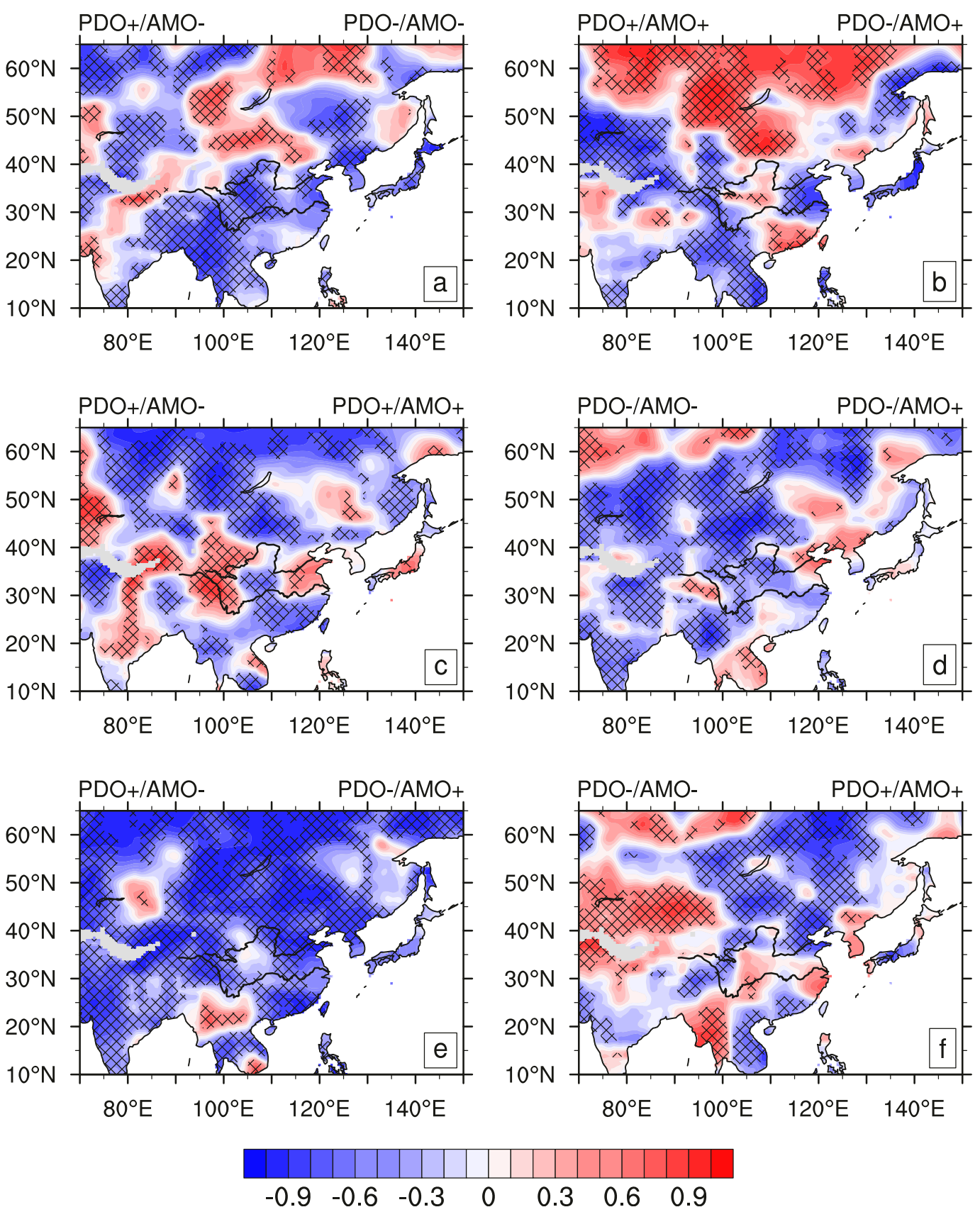

FIG. 4. Moving pattern correlation coefficients of composited JJA precipitation anomalies between any two combined PDO and AMO phases in Fig. 3. Cross-hatched areas indicate significant correlation coefficient at the $95 \%$ confidence level.

and SFND pattern of interdecadal precipitation anomalies (Fig. 1a; Zhu and Yang 2003b). However, in the positive PDO phase but different AMO phases (Figs. 3a,d), the anomalous precipitation patterns are distinct from each other and different from the SFND pattern as well.

Furthermore, to identify the linear effects of combined PDO and AMO phases, the moving pattern correlation is applied on the composite precipitation anomalies in any two pairs of the combined PDO and AMO phases shown in Fig. 3 (Fig. 4). The area with significant negative spatial correlation values indicates that the influence of the two pairs of combined PDO and AMO phases has opposite signs on precipitation anomalies. Otherwise, the results reflect the unstable or nonlinear influences of the two pairs of combined PDO and AMO phases. 

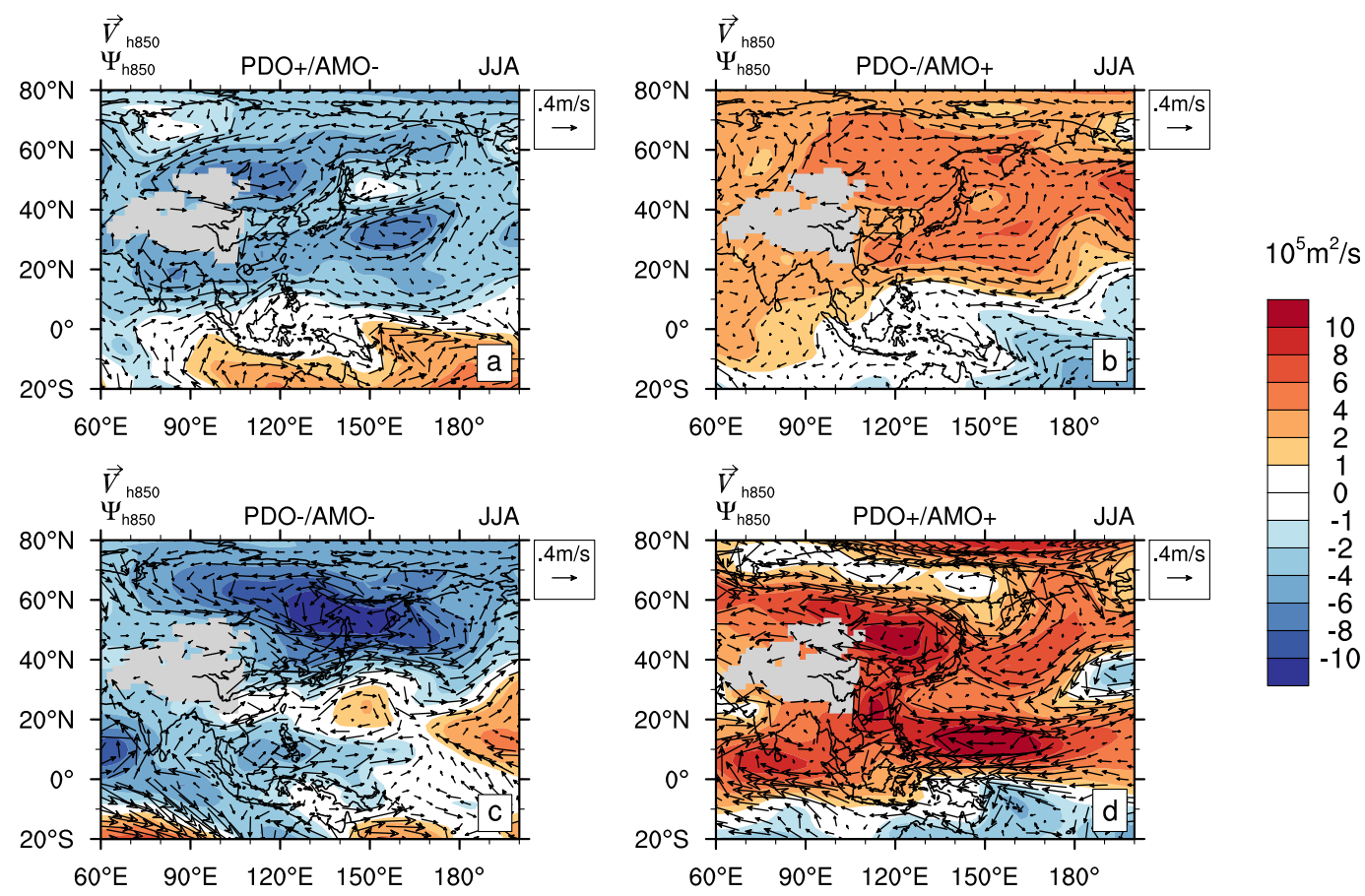

FIG. 5. As in Fig. 2, but for JJA wind vector anomalies (vector, $\mathrm{m} \mathrm{s}^{-1}$ ) and its streamfunction (shading, $10^{5} \mathrm{~m}^{2} \mathrm{~s}^{-1}$ ) at $850 \mathrm{hPa}$.

The moving pattern correlation of precipitation anomalies between the PDO+/AMO - and PDO-/ AMO - phases reflects the linear effect of the PDO under the background of negative AMO phases (Fig. 4a) because the opposite PDO phases are compared in the fixed negative AMO phase. It shows that the PDO can cause completely opposite precipitation anomalies over northeastern China, central China, the HHRV, and Indochina (Fig. 4a). However, in the positive AMO phase, the PDO-affected regions lie mainly over part of northeastern China, the HHRV, and Indochina (Fig. 4b). Therefore, the common PDO-affected regions are the HHRV and Indochina, regardless of AMO phases. By comparing Fig. 4c and Fig. 4d, the key common AMO-affected regions independent of the PDO are mainly located over northern East Asia, such as northern China and regions around Lake Baikal, and the positive relationship of the AMO and southern China precipitation by linear correlation (Fig. 1a; Wang et al. 2009) is only valid in the positive PDO phase (Fig. 4c). In terms of the out-of-phase combination of the PDO and $\mathrm{AMO}(\mathrm{PDO}+/ \mathrm{AMO}-$ vs $\mathrm{PDO}-/ \mathrm{AMO}+$; Fig. 4e), precipitation anomalies over almost all of East Asia and South Asia are highly opposite of each other. Similarly, most of northern East Asia is dominated by the significant linear relationship of precipitation anomalies and the in-phase combination of the PDO and AMO $(\mathrm{PDO}-/ \mathrm{AMO}-\mathrm{vs} \mathrm{PDO}+/ \mathrm{AMO}+)$ (Fig. 4f), and the exceptional regions like the YRV are probably due to either the nonlinear effects of the in-phase combination of the PDO and AMO or the modulation effects of additional IOBM SSTAs (Figs. 2c,d).

\section{c. The low-level atmospheric circulations}

Associated with the composite precipitation anomalies in Fig. 3, Fig. 5 presents the composite low-level atmospheric circulation anomalies, including the wind vectors and streamfunction fields at $850 \mathrm{hPa}$.

When the PDO and AMO are out of phase, the anomalous low-level atmospheric circulations over East Asia are nearly mirrored between the PDO+/AMOand $\mathrm{PDO}-/ \mathrm{AMO}+$ phases (Figs. 5a,b). In the PDO $+/$ AMO- phase (Fig. 5a), both Lake Baikal and the southeast of Japan are characterized by a notable anomalous cyclone together with a low streamfunction anomaly center, and between them is an anomalous ridge in the HHRV. The anomalous cyclone in Lake Baikal appears to be part of a zonally orientated wave train from upstream Eurasia (Fig. 6a), which is responsible for much more precipitation over northern China and south of Lake Baikal and much less precipitation north of Lake Baikal (Fig. 3a). The anomalous cyclone to the southeast of Japan may possibly be caused by the upstream wave trains (Fig. 6a) and the local negative SSTAs (Fig. 2a) caused by the midlatitude air-sea interactions (Zhu and Yang 2003a; Frankignoul 

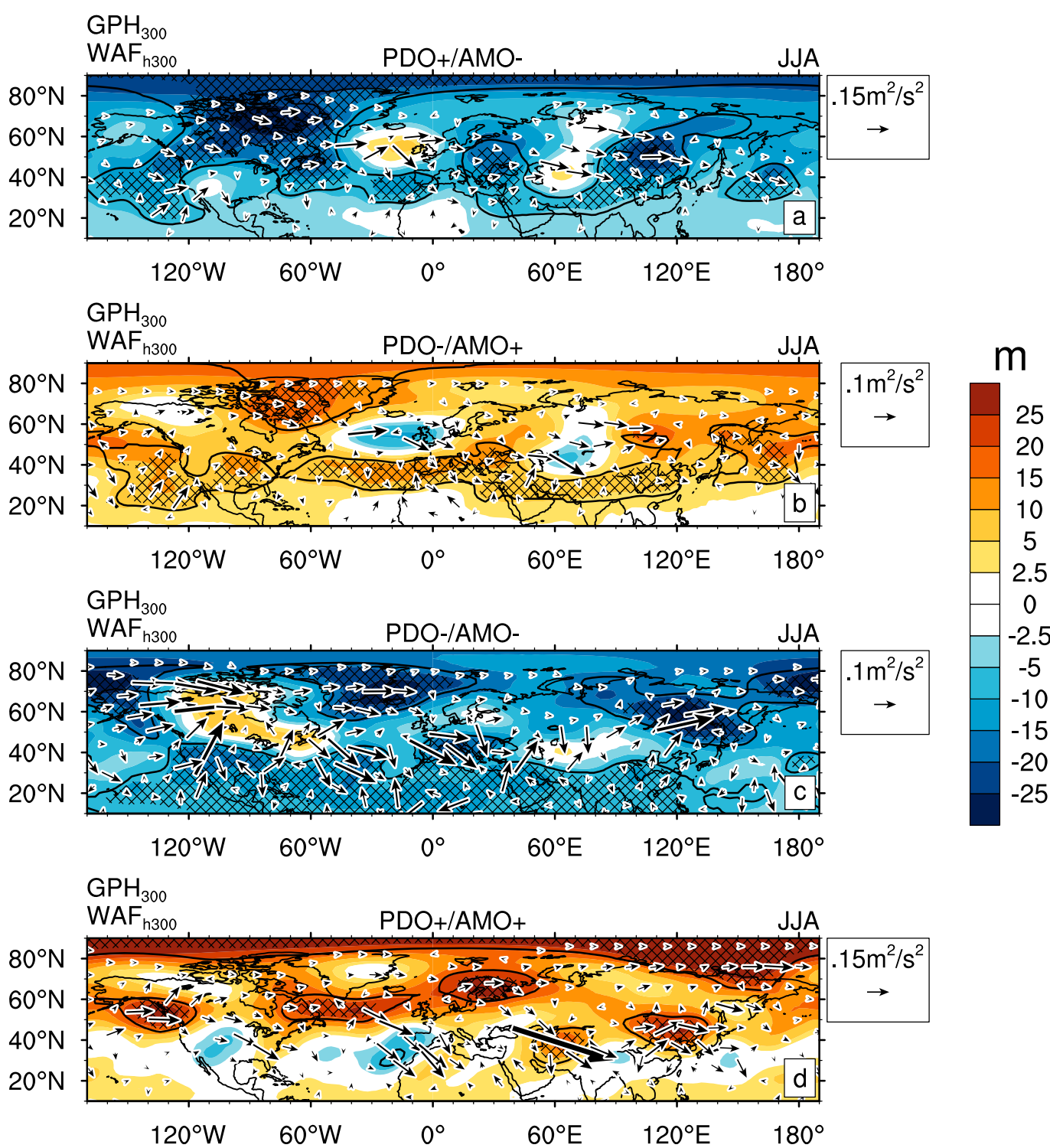

FIG. 6. As in Fig. 2, but for JJA geopotential height anomalies (shading, $\mathrm{m}$ ) and wave activity fluxes (vector, $\mathrm{m}^{2} \mathrm{~s}^{-2}$ ) at $300 \mathrm{hPa}$.

and Sennechael 2007; Zhu et al. 2008; Fang and Yang 2016). It stretches southwestward to southern China and weakens the WPSH and further causes much less precipitation over southern China (Fig. 3a). Under control of the anomalous ridge in the HHRV, much less precipitation occurs over the HHRV than usual (Fig. 3a), which may in turn give feedback on the ridge anomaly ( $\mathrm{Lu}$ and $\mathrm{Lin}$ 2009). In the PDO-/AMO+ phase (Fig. 5b), the anomalous low-level atmospheric circulations are almost opposite to those in the $\mathrm{PDO}+1$ $\mathrm{AMO}$ - phase. Among these, the anomalous ridge in the northwestern Pacific indicates an enhanced and northward-shifted WPSH that brings warm moisture into the HHRV, inducing more precipitation there than usual (Fig. 3b).

When the PDO and AMO are in phase, the anomalous low-level atmospheric circulations are also generally opposite of each other in the PDO+/AMO+ and PDO-/AMO- phases (Figs. 5c,d). In the PDO-/ AMO - phase (Fig. 5c), a strong anomalous anticyclone forms to the southeast of Japan, corresponding to the significant warm SSTAs (Fig. 2c), and it extends westward to the YRV (Fig. 5c). The anomalous anticyclone significantly suppresses precipitation over the YRV with enhanced WPSH; on the other hand, together with the cold dry air from the northwest that is associated with 
the anomalous cyclone in the Sea of Okhotsk, it causes much more precipitation over the HHRV and northern China by conveying moisture from the southwest. As the Kelvin wave response to the reduced ISMP (Fig. 3c) by less diabatic heating release (Matsuno 1966; Gill 1980; Rodwell and Hoskins 2001; Sun et al. 2010; Greatbatch et al. 2013), a notable anomalous cyclone can also be seen in the South China Sea (SCS) and the Philippine Sea. As a result, a clear meridional wave train appears along the coast of East Asia, which is similar to the interdecadal Pacific-Japan (PJ) teleconnection pattern revealed by $\mathrm{Wu}$ et al. (2016b). In the PDO+/AMO+ phase (Fig. 5d), because of the same atmospheric response mechanism, a similar meridional wave train can also be seen over East Asia, but the signs of its anomaly centers get reversed, and the locations are shifted, compared with the PDO-/AMO- phase.

\section{d. The upper large-scale teleconnection wave trains}

To further understand how the combined PDO and AMO phases influence the EASMP anomalies, the composite geopotential height anomalies and their associated wave activity fluxes at $300 \mathrm{hPa}$ are shown in Fig. 6 .

In the PDO+/AMO- phase (Fig. 6a), significant negative anomalies of 300-hPa geopotential height appear over Lake Baikal and the western North Pacific, demonstrating a barotropic structure together with the local anomalous low-level atmospheric circulations. In association with this, there is an obvious zonally oriented circumglobal teleconnection wave train circling the midlatitudes of the Northern Hemisphere, which resembles the interdecadal circumglobal teleconnection pattern (Wu et al. 2016a,b), wherein the part in the North Atlantic-European sector agrees well with the North Atlantic-European east-west (NEW) mode revealed by Ghosh et al. (2017), and the Eurasian continent part is the so-called interdecadal Silk Road pattern (Wang et al. 2017). The eastward wave activity fluxes indicate that the wave train mainly initiates from the North Atlantic and crosses the midlatitudes of the whole Eurasian continent to the North Pacific. As pointed out by Ghosh et al. (2017), the NEW mode is positively correlated with the AMO, and accordingly, the interdecadal Silk Road pattern may be primarily attributed to the negative AMO in the PDO+/AMO- phase. On the other hand, because of the midlatitude air-sea interaction in the North Pacific, the positive PDO in the PDO +/AMO - phase may be responsible for the significant negative anomalies of $300-\mathrm{hPa}$ geopotential height in the western North Pacific (e.g., Fang and Yang 2016). Because of the nearly opposite SSTA patterns in the $\mathrm{PDO}+/ \mathrm{AMO}-$ and $\mathrm{PDO}-/ \mathrm{AMO}+$ phases, the zonally orientated circumglobal teleconnection wave train is almost reversed in the $\mathrm{PDO}-/ \mathrm{AMO}+$ phase (Fig. 6b).

In the PDO-/AMO- phase (Fig. 6c), according to the wave activity flux, the geopotential height anomalies at $300 \mathrm{hPa}$ demonstrate a teleconnection wave train starting from around western central Asia and along a great circle route via the northeast of East Asia, Alaska, and northern North America, reaching the North Atlantic. This northeastward-propagated teleconnection wave train may be stimulated by negative ISMP anomalies (Fig. 3c), similar to the interannual circumglobal teleconnection (Ding et al. 2011; Greatbatch et al. 2013), and further enhanced and relayed by the negative PDO SSTAs in the North Pacific. Furthermore, the Rossby wave energy continuously propagates southeastward from the North Atlantic to western central Asia along a great circle path, resulting in negative ISMP anomalies (Fig. 3c) (Luo et al. 2011). Thus, the ISMP anomalies closely interact with the 300-hPa geopotential height anomalies over western central Asia and further trigger and maintain the teleconnection wave train (Ding and Wang 2005; Ding et al. 2011; Greatbatch et al. 2013). Such kind of teleconnection wave train via the great circle route around the Northern Hemisphere is also detectable in the PDO+/AMO+ phase (Fig. 6d), though its locations and polarities differ somewhat from those in the PDO-/AMO- phase.

Therefore, when the PDO and AMO are out of phase, the circumglobal teleconnection wave train is zonally oriented in the Eurasian midlatitudes, and the anomalous atmospheric circulations are opposite between the $\mathrm{PDO}+/ \mathrm{AMO}-$ and PDO-/AMO+ phases. However, when the PDO and AMO are in phase, the teleconnection wave train is generally oriented along the great circle route in the Northern Hemisphere, and western central Asia is the turning point to connect the wave trains that propagate southeastward and northeastward, separately. Consequently, the ISMP interacts with the midlatitude teleconnection wave trains and becomes another important forcing factor besides the PDO and AMO. However, ISMP can be further partly influenced by the IOBM SSTAs (Kucharski et al. 2006) as well, since the IOBM SSTAs are not negligible when the PDO and AMO are in phase (Figs. 2c,d). For example, due to the offset of cool IOBM effect, the ISMP anomalies are not very significant in Fig. 3c (see also section 5). On the other hand, the 300-hPa geopotential height anomalies are not entirely opposite to each other between the PDO-/AMO - and PDO +/AMO + phases, which is probably due to the complex nonlinear interaction of the oceanic signals (AMO, PDO, and IOBM), as well as the ISMP. In addition, the AMO phase basically determines the sign of anomalous geopotential 

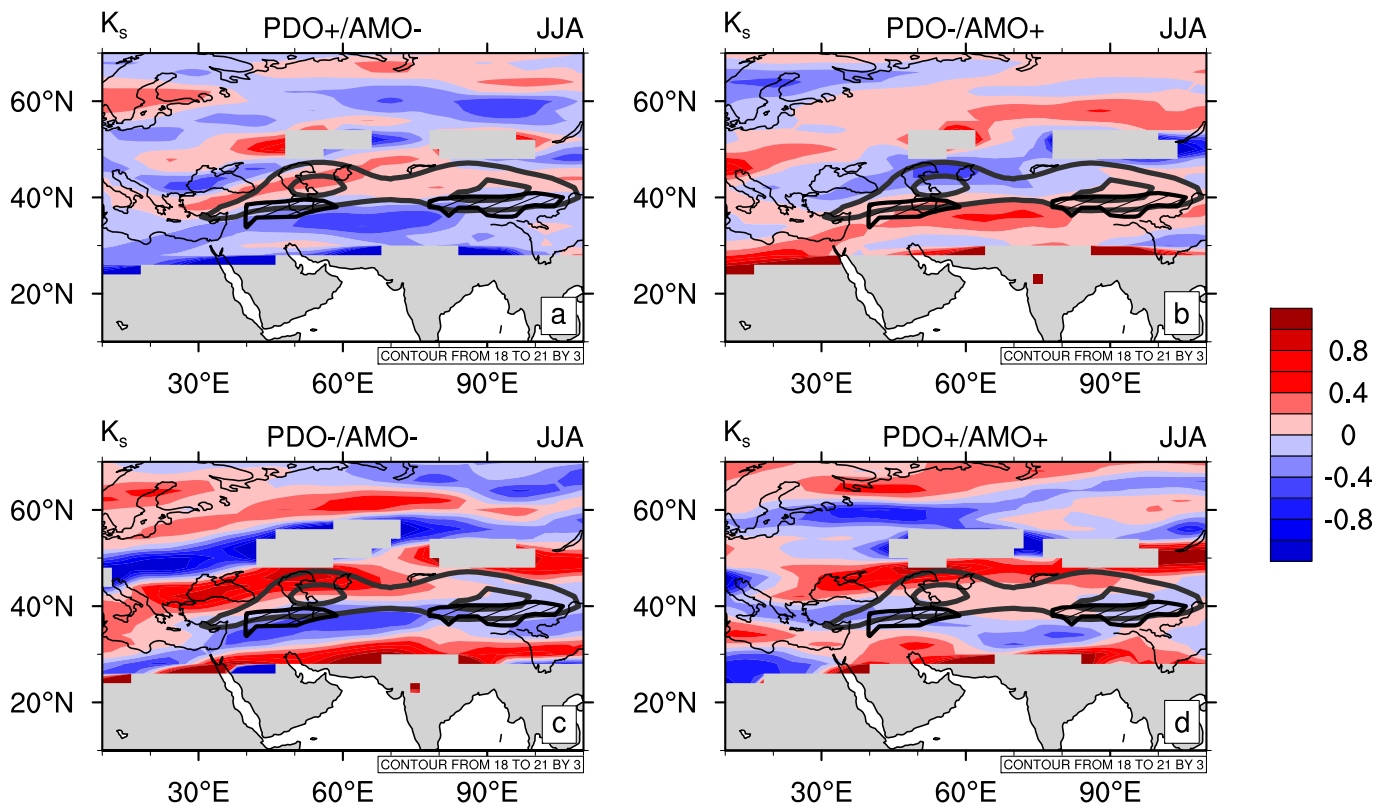

FIG. 7. As in Fig. 2, but for JJA $K_{s}$ anomalies (shading) at $300 \mathrm{hPa}$. The thick contour lines indicate the Asian westerly jet (contour intervals of 18 and $21 \mathrm{~m} \mathrm{~s}^{-1}$ ). The hatched areas bounded by thick black lines denote the Rossby waveguide $\left(K_{s}>7.7\right)$.

height in the Northern Hemisphere, with larger positive (negative) amplitude in the positive (negative) AMO phase, reflecting its strong climate impacts throughout the Northern Hemisphere (Wyatt et al. 2012; Chylek et al. 2014).

\section{e. The stationary Rossby wavenumber diagnoses}

To investigate why the two types of wave trains correspond to the PDO and AMO being out of phase and in phase, the $300-\mathrm{hPa}$ stationary Rossby wavenumber associated with the Rossby waveguide and Rossby wave ray is further diagnosed.

As shown in Fig. 7, climatologically, the summer Asian westerly jet lies at around $40^{\circ} \mathrm{N}$, and there are two jet cores located on the north sides of both the Iranian Plateau (around $50^{\circ} \mathrm{E}$ ) and the Tibetan Plateau (around $90^{\circ} \mathrm{E}$ ). To their south, there exist two obvious Rossby waveguides. When the PDO and AMO are out of phase, the anomalous $K_{s}$ demonstrates a meridional negativepositive-negative "sandwich pattern" in the eastern Mediterranean region (Figs. 7a,b), and it tends to enhance the waveguide because higher $K_{s}$ favors waveguide occurrences (Hoskins and Ambrizzi 1993; Ambrizzi et al. 1995). At the same time, the decrease of $K_{s}$ around $30^{\circ} \mathrm{E}$ to the north of westerly jet will flatten the Rossby wave propagation route, according to the great circle route theory (Hoskins and Karoly 1981). Both of those can induce the anomalous wave train to propagate zonally from the North Atlantic to East Asia along the Asian westerly jet waveguide (Figs. 7a,b). By contrast, when the PDO and AMO are in phase, the $K_{s}$ shows a positive-negativepositive sandwich pattern in the eastern Mediterranean region (Figs. 7c,d), which tends to reduce the effect of the waveguide since the meridional gradient of $K_{s}$ is decreasing. On the other hand, the increase of $K_{s}$ in the north of the westerly jet around $30^{\circ} \mathrm{E}$ bends the great circle route equatorward (Hoskins and Karoly 1981; Hoskins and Ambrizzi 1993). Therefore, the anomalous wave train from the North Atlantic can influence the ISMP, which in turn stimulates a wave train to East Asia by its released diabatic heating (Ding and Wang 2005; Ding et al. 2011; Greatbatch et al. 2013).

\section{Modulation effects of the IOBM}

As mentioned before, the IOBM is another important interdecadal oceanic signal for the EASMP anomalies, especially for the SFND pattern, and it can serve as the background of the PDO and AMO and further modulate their combined impacts.

As shown in both Fig. 1e and Table 2, there are two study periods for the same $\mathrm{PDO}-/ \mathrm{AMO}+$ phase, but with nearly opposite IOBM: 1946-61 and 1999-2010 with significant cooling (Fig. 8c) and warming (Fig. 8a) associated with the IOBM, respectively. Correspondingly, in the period of 1999-2010, the PDO-/AMO+ phase shows significantly less-than-normal precipitation over northern China, but much more precipitation over 

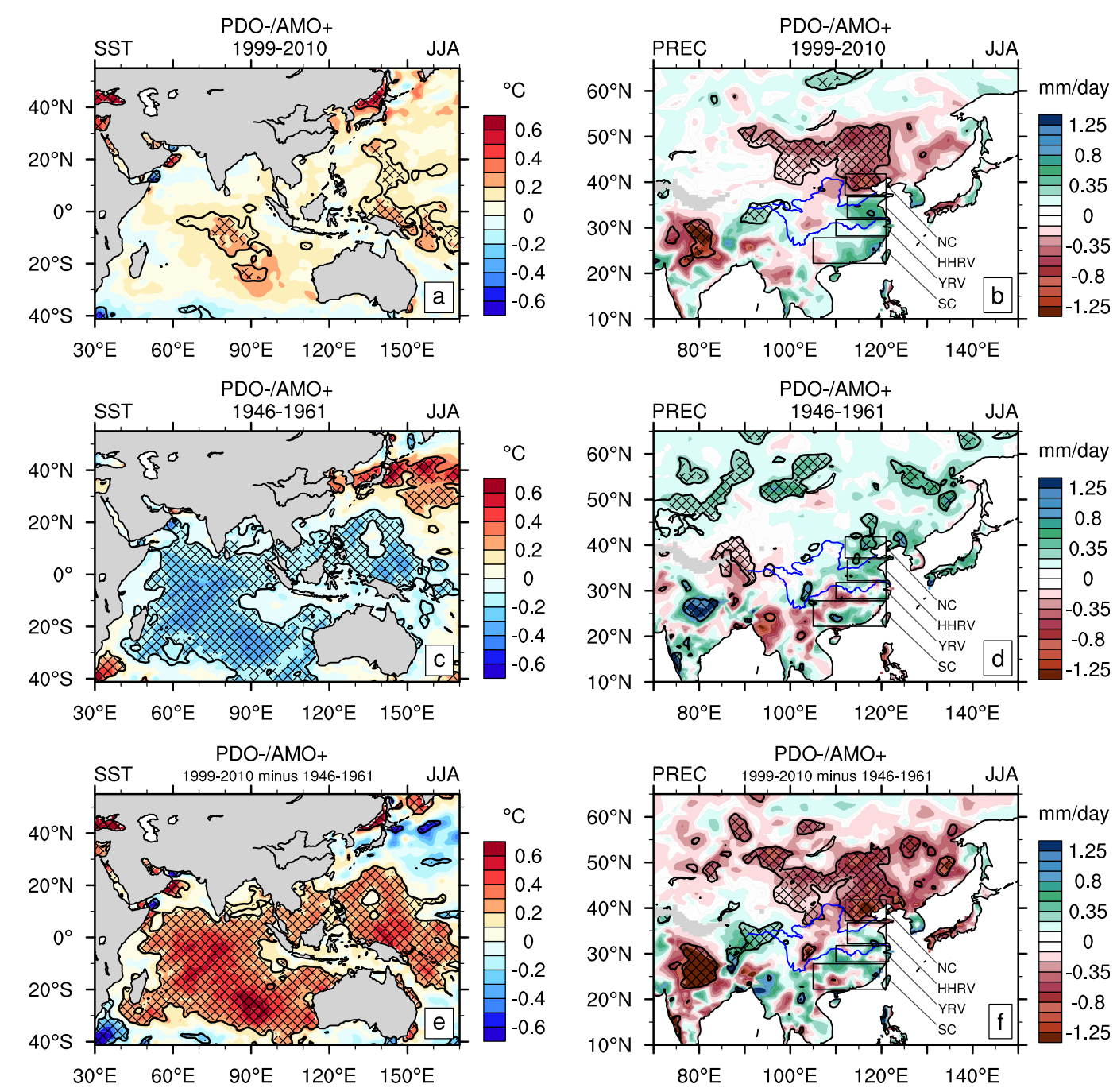

FIG. 8. (left) Composited JJA SSTAs in the Indian-western Pacific Ocean (shading, ${ }^{\circ} \mathrm{C}$ ) and (right) composite JJA precipitation anomalies over Asia (shading, mm day ${ }^{-1}$ ) in (a),(b) 1999-2010 (IOBM warming/PDO-/ AMO+), (c),(d) 1946-61 (IOBM cooling/PDO-/AMO+), and (e),(f) their differences. The $90 \%$ and $95 \%$ confidence levels are denoted by thick black contour lines and cross hatching, respectively.

the HHRV and southern China (Fig. 8b), which is consistent with that in Fig. $3 \mathrm{~b}$ composited by the two periods. However, the anomalous precipitation pattern over northern East Asia is almost reversed in the period of 1946-61, accompanied by the notable dry-to-wet transition of ISMP anomalies (Fig. 8d). From the difference of the two periods (1999-2010 minus 1946-61), the characteristics of both the warming IOBM and significant negative precipitation anomalies over northern East Asia and the Indian subcontinent are much more distinguishable (Figs. 8e,f). Actually, such period difference removes most of the $\mathrm{PDO}-/ \mathrm{AMO}+$ influences and highlights the modulation effects of the IOBM.

IOBM warming (cooling) can induce active (inactive) convection in the tropical Indian Ocean, and by modifying the land-sea thermal contrast (Goswami et al. 2006) and/or the local Hadley circulation (Kucharski et al. 2006; Wang and Mehta 2008), it further greatly suppresses (enhances) the convective activities in the ISM regions (Figs. 9a,c,e), causing much less (more) ISMP (Figs. 8b,d,f) and diabatic cooling (heating), accordingly. As a result, a pair of Rossby waves like the Matsuno-Gill response (Matsuno 1966; Gill 1980) occurs to the southwest of the Indian subcontinent, characterized by a low-level anomalous anticyclone (cyclone) in the Arabian Sea and an anomalous cyclone (anticyclone) in the central-eastern tropical Indian Ocean, and as the Kelvin wave response, there is a strong westerly (easterly) wind anomaly in the SCS-Philippine Sea to their east (Sun et al. 2010; Greatbatch et al. 2013). Furthermore, the 

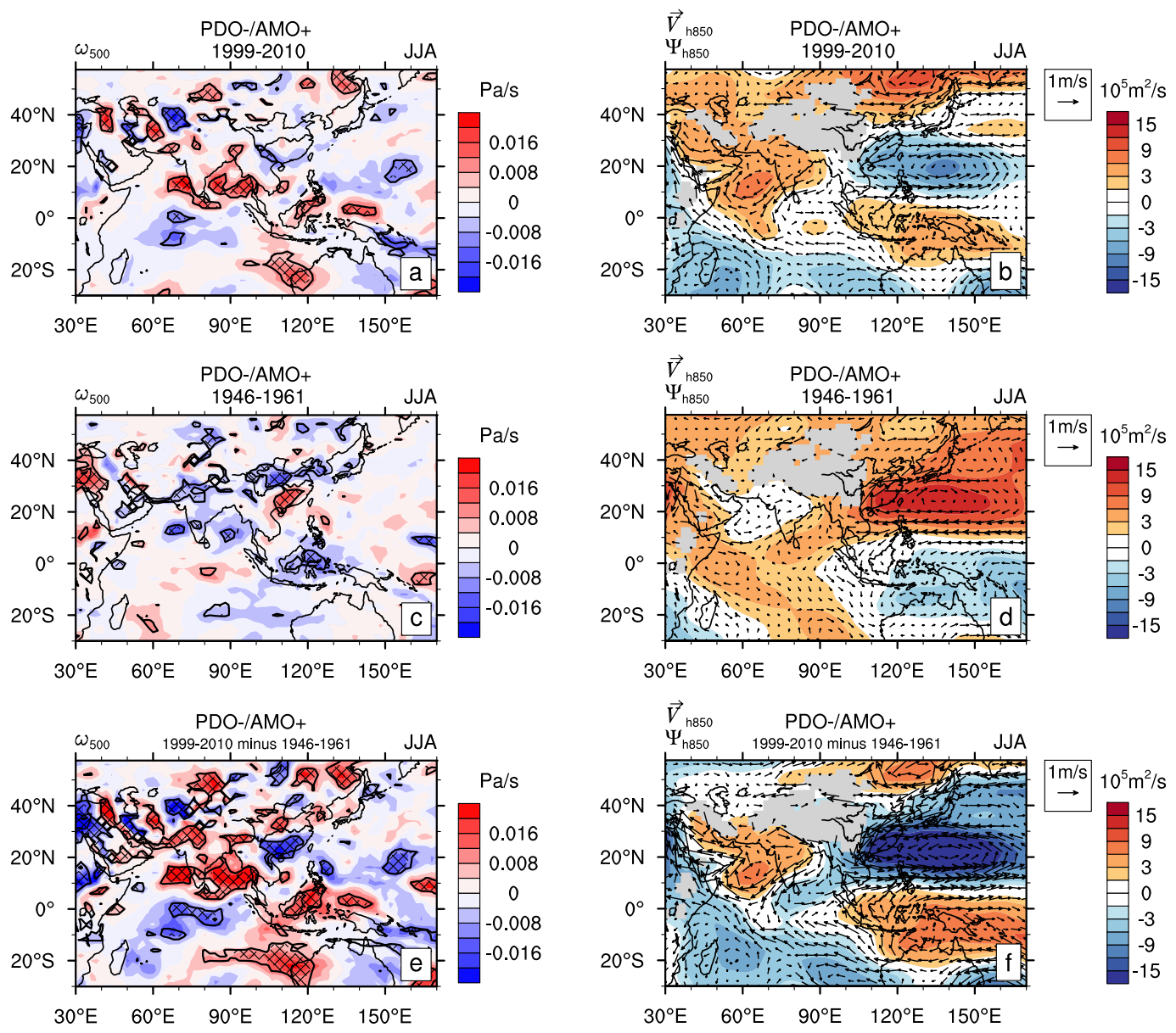

FIG. 9. As in Fig. 8, but for (left) JJA vertical velocity anomalies at $500 \mathrm{hPa}$ in pressure coordinates (shading, $\mathrm{Pa} \mathrm{s}^{-1}$ ) and (right) wind vector anomalies (vector, $\mathrm{m} \mathrm{s}^{-1}$ ) and its streamfunction (shading, $10^{5} \mathrm{~m}^{2} \mathrm{~s}^{-1}$ ) at $850 \mathrm{hPa}$. The $90 \%$ and $95 \%$ confidence levels are denoted by thick black contour lines and cross hatching, respectively.

northerly (southerly) flow over the Bay of Bengal required for Sverdrup vorticity balance contributes to the formation of an anomalous cyclone (anticyclone) in the subtropical northwestern Pacific and southern China (Figs. 9b,d,f) (Rodwell and Hoskins 2001; Zhou et al. 2009). Therefore, when the IOBM is significantly warmed (cooled), the large western Pacific anomalous cyclone (anticyclone) reduces (enhances) the WPSH and favors a weakened (strengthened) EASM, which significantly decreases (increases) the transportation of warm moisture to northern China, and together with the anomalous anticyclone (cyclone) to the east of Lake Baikal, the precipitation over northern China and south of Lake Baikal is significantly decreased (increased) (Figs. 8b,d,f).

The cold IOBM that caused significant the low-level anticyclone anomaly in the northwestern Pacific is similar to the PDO-/AMO+ composite (Fig. 5b). Therefore, cold (warm) IOBM could enhance (counteract and even reverse) the $\mathrm{PDO}-/ \mathrm{AMO}+$ composite atmospheric circulation anomalies in the northwestern Pacific. As a result, a stronger (relatively weaker) northwestern Pacific anticyclone (cyclone) anomaly appears in the 1946-61 (1999-2010) epoch (Figs. 9b,d), suggesting the dominant linear modulation effects of the IOBM over the impacts of the out-of-phase combination of the PDO and AMO. In the upper troposphere, the IOBM basically does not alter the zonal propagation of wave energy over the Eurasian continent in the PDO-/ $\mathrm{AMO}+$ phase; however, it stimulates another stationary Rossby wave train from western central Asia to the North Atlantic along a great circle route (Fig. 10; see Ding and Wang 2005; Sun et al. 2010; Ding et al. 2011; Chu et al. 2013; Greatbatch et al. 2013), especially in the period of 1946-61 (Fig. 10b), when the cool phase of the IOBM is more significant (Fig. 8c). At the same time, the epoch difference shows that the warming (cooling) IOBM has a similar (opposite) teleconnection wave 


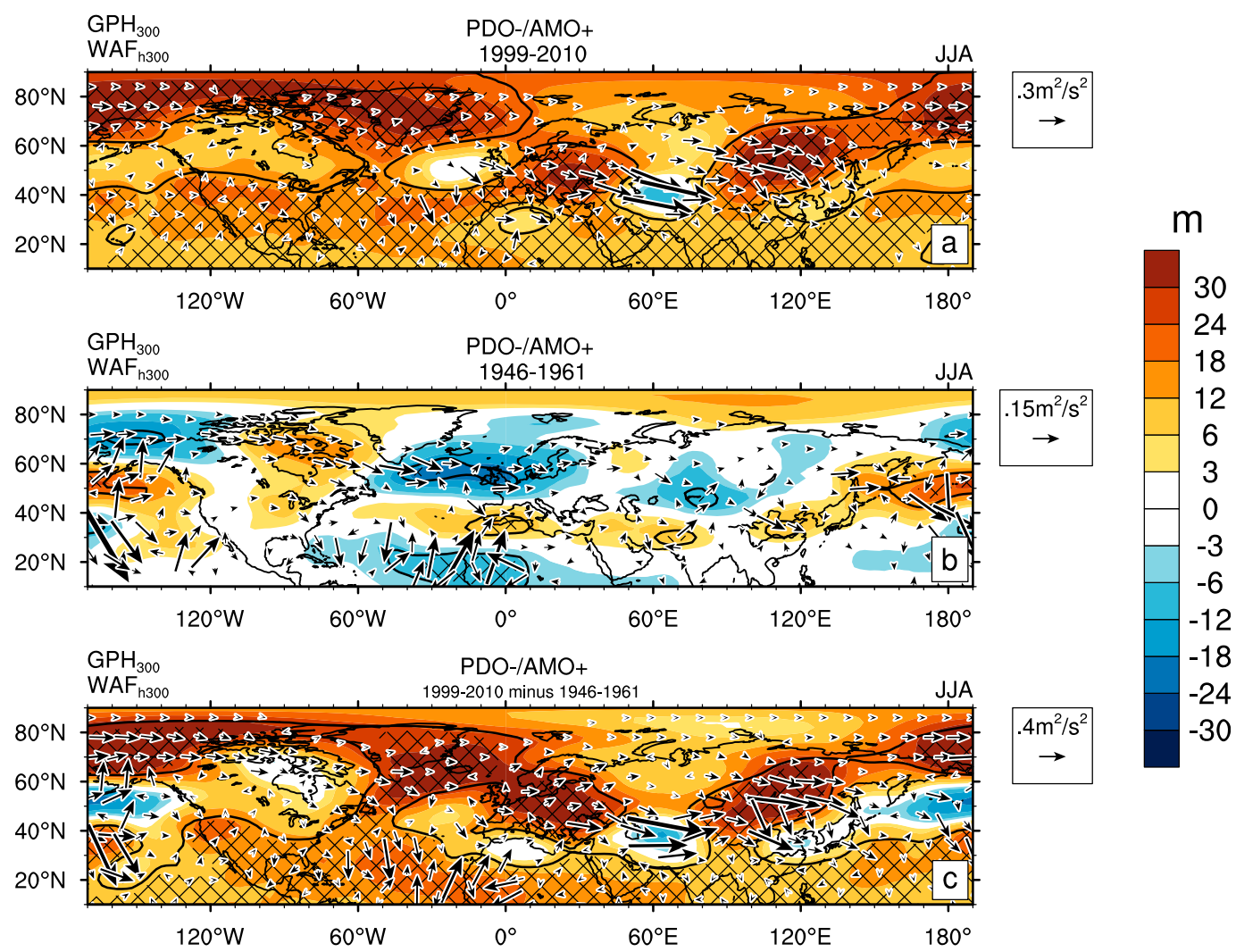

FIG. 10. As in Fig. 8, but for JJA geopotential height anomalies (shading, m) and wave activity fluxes (vector, $\mathrm{m}^{2} \mathrm{~s}^{-2}$ ) at $300 \mathrm{hPa}$. The $90 \%$ and $95 \%$ confidence levels are denoted by thick black contour lines and cross hatching, respectively.

train with the PDO-/AMO+ phase (Figs. 10c and 6b), which causes much stronger upper-tropospheric circulation anomalies in the $\mathrm{PDO}-/ \mathrm{AMO}+$ phase with warming IOBM (Fig. 10a) than those in the PDO-/ $\mathrm{AMO}+$ phase with cooling IOBM (Fig. 10b). Therefore, it can also be easily deduced that the impacts of the IOBM in the upper troposphere are in opposite signs between its warming and cooling phases, and so are its modulation effects on the combined impacts of the PDO and AMO.

As for the in-phase combination of the PDO and AMO demonstrated in section $4 \mathrm{~d}$, besides the IOBM, teleconnection wave trains originated from midlatitude can also influence the ISMP; the PDO-/AMO$(\mathrm{PDO}+/ \mathrm{AMO}+)$ phase favors negative (positive) ISMP anomalies (Figs. 3c,d). As shown in Fig. 2c, there are significant cold SST anomalies in the Indian Ocean in the PDO-/AMO- composite, which can produce positive ISMP anomalies and cancel out part of the negative ISMP anomalies as a result of the impacts of the PDO-/ AMO - phase. Nevertheless, since the AMO has a statistically positive relation with the ISMP (Goswami et al. 2006; Wang et al. 2009; Luo et al. 2011), it still shows overall negative precipitation anomalies over the Indian subcontinent (Fig. 3c), suggesting the ISMP is mainly influenced by the midlatitude wave trains from the upstream Atlantic rather than the IOBM. That is the reason why the ISMP anomalies are not significant in Fig. 3c.

\section{Conclusions and discussion}

On the interdecadal time scale, the EASMP anomalies are so complicated that they cannot be explained by each of the three dominant oceanic signals (i.e., PDO, AMO, and IOBM) separately. Therefore, the joint influence of the PDO, AMO, and IOBM on the interdecadal EASMP anomalies is considered and investigated in this study, with century-long datasets of HadISST, CRU precipitation, and ERA-20C.

Because of the different scales associated with the PDO, AMO, and IOBM, their positive and negative phases are overlapped with each other, so the nearcentury-long study period (1925-2010) is divided into four pairs of combined PDO and AMO phases: $\mathrm{PDO}+1$ $\mathrm{AMO}-, \mathrm{PDO}-/ \mathrm{AMO}-, \mathrm{PDO}+/ \mathrm{AMO}+$, and $\mathrm{PDO}-/$ $\mathrm{AMO}+($ Table 2). Correspondingly, the anomalies of 
SST, precipitation, and atmospheric circulation are composited and analyzed and associated with the different phase combinations of the PDO and AMO. The major characteristics of the EASMP anomalies are attributed to two types of teleconnection wave trains: the zonally oriented circumglobal teleconnection wave train along the Asian westerly jet waveguide and the teleconnection wave train along the great circle route that involves interaction with the ISMP. Meanwhile, the AMO has an overwhelming impact on the Northern Hemisphere atmosphere, generally increasing (decreasing) the hemispherical geopotential height as a whole in the positive (negative) phase. Based on the theories of Rossby waveguide and Rossby wave rays, the pattern of anomalous $K_{s}$ in the eastern Mediterranean region around $30^{\circ} \mathrm{E}$ is found to be the key in determining the type of teleconnection wave train. By inducing the ISMP anomalies, the IOBM exerts significant linear modulation on the combined impacts of the PDO and AMO. The specific mechanisms for the joint influence of the PDO, AMO, and IOBM on the interdecadal EASMP anomalies are summarized by a schematic diagram in Fig. 11.

When the PDO and AMO are out of phase (Figs. 11a,b), the North Pacific and North Atlantic are both dominated by the same-sign SSTAs, which prevails in the recent 100 years (Kosaka 2018). Accordingly, a negative-positive-negative "sandwich" pattern of anomalous $K_{s}$ appears in the eastern Mediterranean region; it enhances the waveguide and forms a zonally orientated circumglobal Rossby wave train from the North Atlantic to the North Pacific across the Eurasian midlatitudes, which links the AMO-related North Atlantic-European east-west mode (Ghosh et al. 2017) and the PDO-related North Pacific barotropic atmospheric circulations, together causing a meridional tripole mode of interdecadal precipitation anomalies over eastern China. The anomalies of precipitation and atmospheric circulations are in opposite sign to each other between the PDO+/AMO - and PDO-/ $\mathrm{AMO}+$ phases.

When the PDO and AMO are in phase (Figs. 11c,d), the North Pacific and North Atlantic feature oppositesign SSTAs. In this situation, the $K_{s}$ shows a positivenegative-positive sandwich pattern in the eastern Mediterranean region, which reduces the effect of waveguide and bends the wave train equatorward along the great circle route, causing ISMP anomalies. The ISMP anomalies, in turn, interact with the teleconnection wave train caused by the in-phase combination of the PDO and AMO and cause a meridional dipole mode of interdecadal precipitation anomalies over eastern China. However, with the ISMP involved, the impacts on atmospheric circulations and the EASMP do not simply change sign between the $\mathrm{PDO}+/ \mathrm{AMO}+$ and PDO-/AMO - phases.

The ISMP also plays a crucial role in linking the IOBM and its related interdecadal atmospheric circulations and EASMP anomalies (Fig. 11e). Much less (more) ISMP corresponds to the warm (cold) phase of the IOBM resulting from the decreased (increased) land-sea thermal contrast. It can stimulate a Rossby wave train from western central Asia to the North Atlantic across East Asia and the North Pacific in the upper troposphere. At the same time, a large, strong, low-level anomalous cyclone (anticyclone) anomaly dominates in the northwestern Pacific as the Kelvin wave response, which greatly reduces (enhances) the WPSH and weakens (strengthens) the EASM, causing a typical SFND pattern over eastern China. The impact of the IOBM on the atmospheric circulations and EASMP anomalies changes sign with the sign of the index and exerts linear modulations on the combined impacts of the PDO and AMO, especially over northern East Asia. The modulation effects of the IOBM on the ISMP anomalies and associated atmospheric circulation anomalies depend on different phase combinations of the PDO and AMO. When the PDO and AMO are out of phase, the ISMP anomalies hardly have influences from the midlatitude because of the out-of-phase combination of the PDO and AMO, and the IOBM dominates the ISMP anomalies and the atmospheric circulation anomalies in the northwestern Pacific as well. When they are in phase, the ISMP anomalies are mainly determined by the in-phase combination of the PDO and AMO, and the IOBM plays a second role.

Therefore, by considering the PDO-AMO phase combinations and the linear modulation of the IOBM, the observed spatial and temporal interdecadal variability of EASMP anomalies can be well understood. And based on the results in this study, it is possible to make predictions for the interdecadal EASMP anomalies based on the combined phases of the PDO, AMO, and IOBM. Regarding the ongoing warming of the IOBM accompanied by negative PDO and warm AMO, recent severe drought over northern China will probably continue and get even worse, whereas much more precipitation will occur over southeastern China, like the lower reaches of the YRV and southern China. With PDO turning into a warm phase, the interdecadal summer precipitation over the HHRV will further become much less than normal as well as northern China, suggesting a large area of severe drought over northern China in the next decade, at least. However, the current state-of-the-art models are lacking skill in the decadal prediction of EASMP anomalies, especially over 
(a)

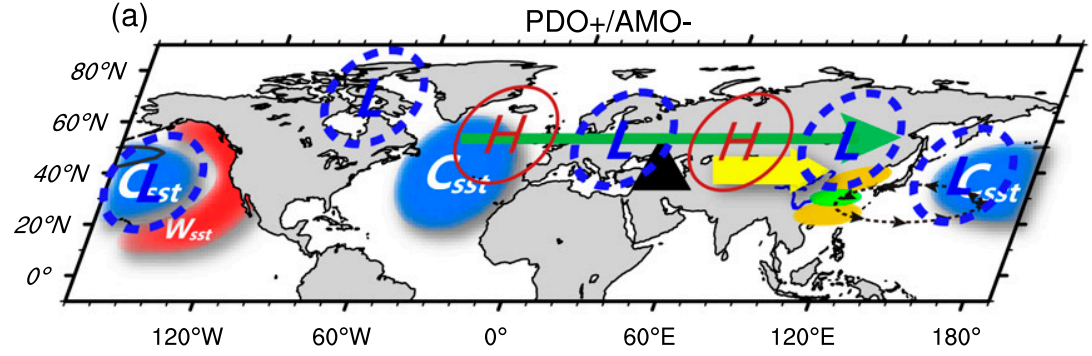

(b)

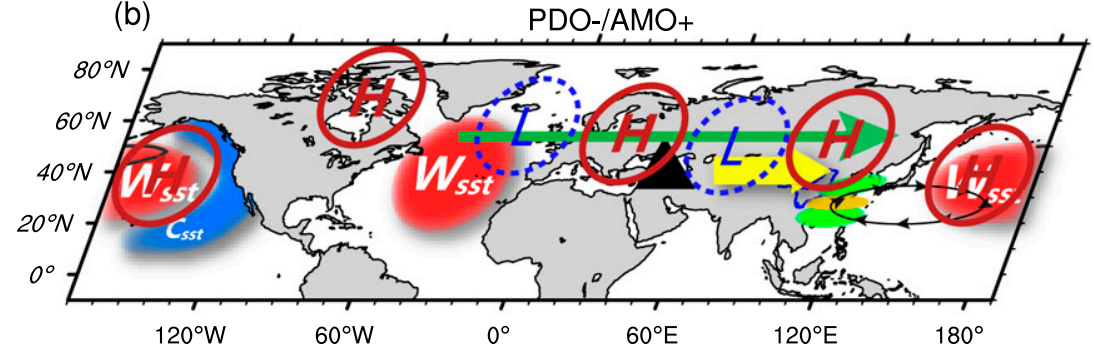

(c)

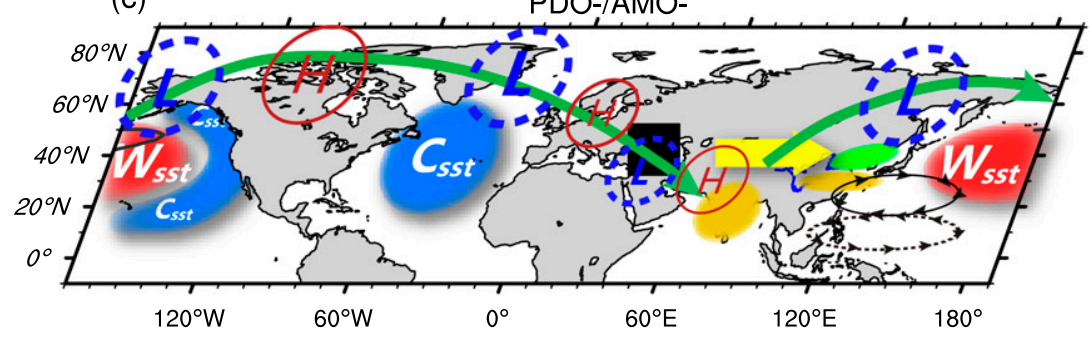

(d)

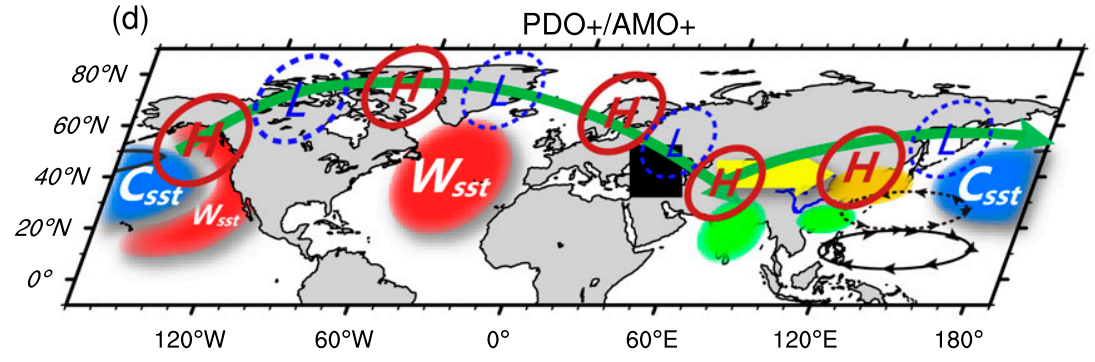

(e)

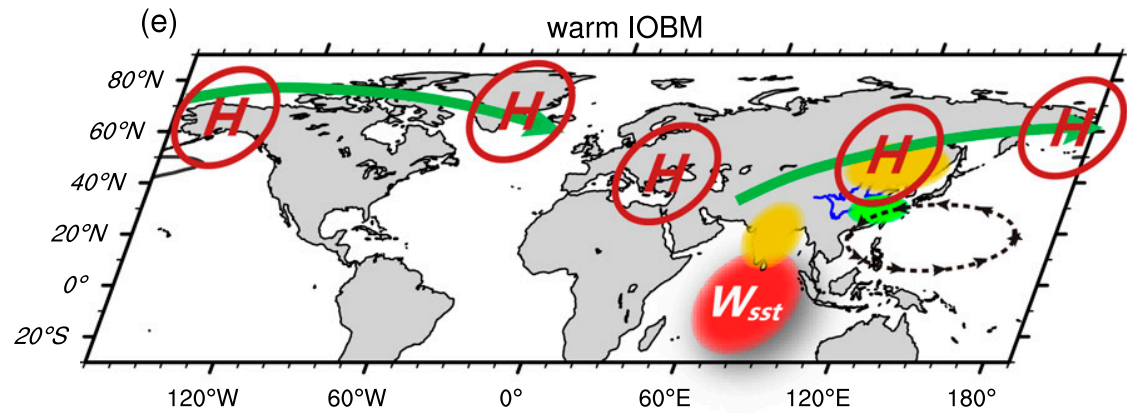

FIG. 11. Schematic diagram of the joint influence of the PDO, AMO, and IOBM on the interdecadal variability of the EASMP. The red (blue) shaded area denotes the warm (cold) SSTA, while the green (brown) shaded area indicates increased (decreased) precipitation; the solid (dashed) black circle with arrow heads denotes the low-level anticyclone (cyclone) anomaly, while the solid red (dashed blue) circle indicates the positive (negative) geopotential height anomaly at $300 \mathrm{hPa}$. The solid green arrow denotes the propagation of the teleconnection wave train, while the shaded yellow arrow indicates the climatological Asian westerly jet waveguide. Shaded triangles and squares indicate the key region where the two types of teleconnection wave trains form resulting from different sandwich patterns of anomalous $K_{s}$ in the eastern Mediterranean region around $30^{\circ} \mathrm{E}$. 
northern East Asia (Meehl et al. 2014), where our statistical results have more confidence. The problems are mainly attributed to the limited capabilities of the stateof-the-art models in simulating and forecasting the PDO and AMO (Ding et al. 2013; Meehl et al. 2014; Han et al. 2016; Newman et al. 2016) and reproducing the atmospheric teleconnections (Lin et al. 2016) as well, which are all essential for the interdecadal EASMP variability, as illustrated in this study. However, recent approaches have been developed to improve the prediction skill of the PDO (Ding et al. 2013; Thoma et al. 2015), which could also shed light on the prediction of future EASMP changes.

However, we are also aware that there are still some deficiencies in explaining the interdecadal EASMP variability with the joint influence of the PDO, AMO, and IOBM, especially in southern East Asia (Figs. 1a,e). It may be due to the absence of other interdecadal oceanic forcing signals: for instance, the North Pacific Gyre Oscillation (Di Lorenzo et al. 2008; Ye et al. 2016) and the interdecadal southern Indian Ocean mode (Zhang et al. 2017), which could also have some important impacts on the interdecadal EASMP anomalies (Ye et al. 2016; Zhang et al. 2017). On the other hand, given the relatively weak significance in composites because of the short observational record $(80 \mathrm{yr}$ at most), the proposed mechanisms need to be verified and confirmed with much longer observations and elegant numerical experiments in future.

Acknowledgments. This work was jointly funded by the National Natural Science Foundation of China (Grants 41621005, 41775074, 41275069, and 41330420) and the Fundamental Research Funds for the Central Universities (020714380035).

\section{REFERENCES}

Ambrizzi, T., B. J. Hoskins, and H.-H. Hsu, 1995: Rossby wave propagation and teleconnection patterns in the austral winter. J. Atmos. Sci., 52, 3661-3672, https://doi.org/10.1175/ 1520-0469(1995)052<3661:RWPATP $>2.0 . C O ; 2$.

Branstator, G., 2002: Circumglobal teleconnections, the jet stream waveguide, and the North Atlantic Oscillation. J. Climate, 15, 1893-1910, https://doi.org/10.1175/1520-0442(2002)015<1893: CTTJSW $>2.0 . \mathrm{CO} ; 2$.

Bretherton, C. S., M. Widmann, V. P. Dymnikov, J. M. Wallace, and I. Bladé, 1999: The effective number of spatial degrees of freedom of a time-varying field. J. Climate, 12, 1990-2009, https://doi.org/ 10.1175/1520-0442(1999)012<1990:TENOSD>2.0.CO;2.

Chelton, D. B., and C. M. Risien, 2016: Zonal and meridional discontinuities and other issues with the HadISST1.1 dataset. Oregon State University Tech. Rep., 18 pp., http://ir.library. oregonstate.edu/concern/defaults/kw52j9632.

Chu, C., X.-Q. Yang, X. Ren, and T. Zhou, 2013: Response of Northern Hemisphere storm tracks to Indian-western
Pacific Ocean warming in atmospheric general circulation models. Climate Dyn., 40, 1057-1070, https://doi.org/10.1007/ s00382-013-1687-y.

Chylek, P., J. D. Klett, G. Lesins, M. K. Dubey, and N. Hengartner, 2014: The Atlantic multidecadal oscillation as a dominant factor of oceanic influence on climate. Geophys. Res. Lett., 41, 1689-1697, https://doi.org/10.1002/2014GL059274.

Di Lorenzo, E., and Coauthors, 2008: North Pacific Gyre Oscillation links ocean climate and ecosystem change. Geophys. Res. Lett., 35, L08607, https://doi.org/10.1029/2007GL032838.

Ding, H., R. J. Greatbatch, M. Latif, W. Park, and R. Gerdes, 2013: Hindcast of the $1976 / 77$ and $1998 / 99$ climate shifts in the Pacific. J. Climate, 26, 7650-7661, https://doi.org/10.1175/ JCLI-D-12-00626.1.

Ding, Q., and B. Wang, 2005: Circumglobal teleconnection in the Northern Hemisphere summer. J. Climate, 18, 3483-3505, https://doi.org/10.1175/JCLI3473.1.

, — , J. M. Wallace, and G. Branstator, 2011: Tropicalextratropical teleconnections in boreal summer: Observed interannual variability. J. Climate, 24, 1878-1896, https://doi.org/ 10.1175/2011JCLI3621.1

Ding, Y., Z. Wang, and Y. Sun, 2008: Inter-decadal variation of the summer precipitation in east China and its association with decreasing Asian summer monsoon. Part I: Observed evidences. Int. J. Climatol., 28, 1139-1161, https://doi.org/10.1002/joc.1615.

Dong, L., T. Zhou, A. Dai, F. Song, B. Wu, and X. Chen, 2016: The footprint of the inter-decadal Pacific oscillation in Indian Ocean sea surface temperatures. Sci. Rep., 6, 21251, https:// doi.org/10.1038/srep21251.

Enfield, D. B., A. M. Mestas-Nuñez, and P. J. Trimble, 2001: The Atlantic multidecadal oscillation and its relation to rainfall and river flows in the continental U.S. Geophys. Res. Lett., 28 , 2077-2080, https://doi.org/10.1029/2000GL012745.

Fang, J., and X.-Q. Yang, 2016: Structure and dynamics of decadal anomalies in the wintertime midlatitude North Pacific oceanatmosphere system. Climate Dyn., 47, 1989-2007, https://doi.org/ 10.1007/s00382-015-2946-x.

Frankignoul, C., and N. Sennéchael, 2007: Observed influence of North Pacific SST anomalies on the atmospheric circulation. J. Climate, 20, 592-606, https://doi.org/10.1175/JCLI4021.1.

Ghosh, R., W. A. Müller, J. Baehr, and J. Bader, 2017: Impact of observed North Atlantic multidecadal variations to European summer climate: A linear baroclinic response to surface heating. Climate Dyn., 48, 3547-3563, https://doi.org/10.1007/ s00382-016-3283-4.

Gill, A. E., 1980: Some simple solutions for heat-induced tropical circulation. Quart. J. Roy. Meteor. Soc., 106, 447-462, https:// doi.org/10.1002/qj.49710644905.

Gong, D.-Y., and C.-H. Ho, 2002: Shift in the summer rainfall over the Yangtze River valley in the late 1970s. Geophys. Res. Lett., 29, 1436, https://doi.org/10.1029/2001GL014523.

Goswami, B. N., M. S. Madhusoodanan, C. P. Neema, and D. Sengupta, 2006: A physical mechanism for North Atlantic SST influence on the Indian summer monsoon. Geophys. Res. Lett., 33, L02706, https://doi.org/10.1029/2005GL024803.

Greatbatch, R. J., X. Sun, and X.-Q. Yang, 2013: Impact of variability in the Indian summer monsoon on the East Asian summer monsoon. Atmos. Sci. Lett., 14, 14-19, https://doi.org/ 10.1002/asl2.408.

Han, W., J. Vialard, M. J. McPhaden, T. Lee, Y. Masumoto, M. Feng, and W. P. M. De Ruijter, 2014: Indian Ocean decadal variability: A review. Bull. Amer. Meteor. Soc., 95, 1679-1703, https://doi.org/10.1175/BAMS-D-13-00028.1. 
Han, Z., F. Luo, S. Li, Y. Gao, T. Furevik, and L. Svendsen, 2016: Simulation by CMIP5 models of the Atlantic multidecadal oscillation and its climate impacts. Adv. Atmos. Sci., 33, 13291342, https://doi.org/10.1007/s00376-016-5270-4.

Harris, I., P. D. Jones, T. J. Osborn, and D. H. Lister, 2014: Updated high-resolution grids of monthly climatic observations-The CRU TS3.10 dataset. Int. J. Climatol., 34, 623-642, https://doi.org/ 10.1002/joc.3711.

Hoskins, B. J., and D. J. Karoly, 1981: The steady linear response of a spherical atmosphere to thermal and orographic forcing. J. Atmos. Sci., 38, 1179-1196, https://doi.org/10.1175/ 1520-0469(1981)038<1179:TSLROA > 2.0.CO;2.

_- and T. Ambrizzi, 1993: Rossby wave propagation on a realistic longitudinally varying flow. J. Atmos. Sci., 50, 1661-1671, https://doi.org/10.1175/1520-0469(1993)050<1661: RWPOAR $>2.0 . \mathrm{CO} ; 2$.

—_, and M. J. Rodwell, 1995: A model of the Asian summer monsoon. Part I: The global scale. J. Atmos. Sci., 52, 13291340, https://doi.org/10.1175/1520-0469(1995)052<1329: AMOTAS $>2.0 . \mathrm{CO} ; 2$.

Hu, Z.-Z., 1997: Interdecadal variability of summer climate over East Asia and its association with $500 \mathrm{hPa}$ height and global sea surface temperature. J. Geophys. Res., 102, 19 403-19412, https://doi.org/10.1029/97JD01052.

Huang, R., R. Cai, J. Chen, and L. Zhou, 2006: Interdecadal variations of drought and flooding disasters in China and their association with the East Asian climate system (in Chinese). Chin. J. Atmos. Sci., 30, 730-743.

- , J. Chen, and Y. Liu, 2011: Interdecadal variation of the leading modes of summertime precipitation anomalies over eastern China and its association with water vapor transport over East Asia (in Chinese). Chin. J. Atmos. Sci., 35, 589-606.

-, Y. Liu, and T. Feng, 2013: Interdecadal change of summer precipitation over eastern China around the late-1990s and associated circulation anomalies, internal dynamical causes. Chin. Sci. Bull., 58, 1339-1349, https://doi.org/10.1007/ s11434-012-5545-9.

Jiang, G. X., and X. G. Sun, 2016: Application of d precipitation datasets in summer precipitation variability over east China. J. Meteor. Sci., 36, 448-456.

Kerr, R. A., 2000: A North Atlantic climate pacemaker for the centuries. Science, 288, 1984-1985, https://doi.org/10.1126/ science.288.5473.1984.

Kim, C.-J., W. Qian, H.-S. Kang, and D.-K. Lee, 2010: Interdecadal variability of East Asian summer monsoon precipitation over 220 years (1777-1997). Adv. Atmos. Sci., 27, 253-264, https:// doi.org/10.1007/s00376-009-8079-6.

Kosaka, Y., 2018: Slow warming and the ocean see-saw. Nat. Geosci., 11, 12-13, https://doi.org/10.1038/s41561-017-0038-8.

Kripalani, R. H., and A. Kulkarni, 1997: Rainfall variability over south-east Asia-Connections with Indian monsoon and ENSO extremes: New perspectives. Int. J. Climatol., 17, 11551168, https://doi.org/10.1002/(SICI)1097-0088(199709)17: $11<1155::$ AID-JOC188>3.0.CO;2-B.

Krishnamurthy, V., and B. N. Goswami, 2000: Indian monsoonENSO relationship on interdecadal timescale. J. Climate, 13, 579-595, https://doi.org/10.1175/1520-0442(2000)013<0579: IMEROI $>2.0 . \mathrm{CO} ; 2$

Kucharski, F., F. Molteni, and J. H. Yoo, 2006: SST forcing of decadal Indian monsoon rainfall variability. Geophys. Res. Lett., 33, L03709, https://doi.org/10.1029/2005GL025371.

— - A. Bracco, J. H. Yoo, and F. Molteni, 2007: Low-frequency variability of the Indian monsoon-ENSO relationship and the tropical Atlantic: The "weakening" of the 1980s and 1990s. J. Climate, 20, 4255-4266, https://doi.org/10.1175/JCLI4254.1. - — - - A. M. Tompkins, L. Feudale, P. Ruti, and A. Dell'Aquila, 2009: A Gill-Matsuno-type mechanism explains the tropical Atlantic influence on African and Indian monsoon rainfall. Quart. J. Roy. Meteor. Soc., 135, 569-579, https://doi.org/10.1002/qj.406.

Kwon, M., J.-G. Jhun, and K.-J. Ha, 2007: Decadal change in East Asian summer monsoon circulation in the mid-1990s. Geophys. Res. Lett., 34, L21706, https://doi.org/10.1029/ 2007 GL031977.

Li, X., S.-P. Xie, S. T. Gille, and C. Yoo, 2016: Atlantic-induced pan-tropical climate change over the past three decades. Nat. Climate Change, 6, 275-279, https://doi.org/10.1038/ nclimate2840.

Li, Y., Y. Ding, and W. Li, 2017: Interdecadal variability of the Afro-Asian summer monsoon system. Adv. Atmos. Sci., 34, 833-846, https://doi.org/10.1007/s00376-017-6247-7.

Lin, J.-S., B. Wu, and T.-J. Zhou, 2016: Is the interdecadal circumglobal teleconnection pattern excited by the Atlantic multidecadal oscillation? Atmos. Ocean. Sci. Lett., 9, 451-457, https:// doi.org/10.1080/16742834.2016.1233800.

Lu, R., and Z. Lin, 2009: Role of subtropical precipitation anomalies in maintaining the summertime meridional teleconnection over the western North Pacific and East Asia. J. Climate, 22, 2058-2072, https://doi.org/10.1175/2008JCLI2444.1.

- B. Dong, and H. Ding, 2006: Impact of the Atlantic multidecadal oscillation on the Asian summer monsoon. Geophys. Res. Lett., 33, L24701, https://doi.org/10.1029/2006GL027655.

Luo, F., S. Li, and T. Furevik, 2011: The connection between the Atlantic multidecadal oscillation and the Indian summer monsoon in Bergen climate model version 2.0. J. Geophys. Res., 116, D19117, https://doi.org/10.1029/2011JD015848.

Mantua, N. J., and S. R. Hare, 2002: The Pacific decadal oscillation. J. Oceanogr., 58, 35-44, https://doi.org/10.1023/A 1015820616384.

—_ - Y Y. Zhang, J. M. Wallace, and R. C. Francis, 1997: A Pacific interdecadal climate oscillation with impacts on salmon production. Bull. Amer. Meteor. Soc., 78, 10691079, https://doi.org/10.1175/1520-0477(1997)078<1069: APICOW $>2.0 . \mathrm{CO} ; 2$.

Matsuno, T., 1966: Quasi-geostrophic motions in the equatorial area. J. Meteor. Soc. Japan, 44, 25-43, https://doi.org/10.2151/ jmsj1965.44.1_25.

McCabe, G. J., M. A. Palecki, and J. L. Betancourt, 2004: Pacific and Atlantic Ocean influences on multidecadal drought frequency in the United States. Proc. Natl. Acad. Sci. USA, 101, 4136-4141, https://doi.org/10.1073/pnas.0306738101.

McGregor, S., A. Timmermann, M. F. Stuecker, M. H. England, M. Merrifield, F.-F. Jin, and Y. Chikamoto, 2014: Recent Walker circulation strengthening and Pacific cooling amplified by Atlantic warming. Nat. Climate Change, 4, 888-892, https:// doi.org/10.1038/nclimate2330.

Meehl, G. A., and Coauthors, 2014: Decadal climate prediction: An update from the trenches. Bull. Amer. Meteor. Soc., 95, 243 267, https://doi.org/10.1175/BAMS-D-12-00241.1.

Newman, M., and Coauthors, 2016: The Pacific decadal oscillation, revisited. J. Climate, 29, 4399-4427, https://doi.org/10.1175/ JCLI-D-15-0508.1.

Nigam, S., B. Guan, and A. Ruiz-Barradas, 2011: Key role of the Atlantic multidecadal oscillation in 20th century drought and wet periods over the Great Plains. Geophys. Res. Lett., 38, L16713, https://doi.org/10.1029/2011GL048650. 
Poli, P., and Coauthors, 2016: ERA-20C: An atmospheric reanalysis of the twentieth century. J. Climate, 29, 4083-4097, https://doi.org/10.1175/JCLI-D-15-0556.1.

Power, S., T. Casey, C. Folland, A. Colman, and V. Mehta, 1999: Inter-decadal modulation of the impact of ENSO on Australia. Climate Dyn., 15, 319-324, https://doi.org/10.1007/ s003820050284.

Rayner, N. A., D. E. Parker, E. B. Horton, C. K. Folland, L. V. Alexander, D. P. Rowell, E. C. Kent, and A. Kaplan, 2003: Global analyses of sea surface temperature, sea ice, and night marine air temperature since the late nineteenth century. J. Geophys. Res., 108, 4407, https://doi.org/10.1029/ 2002JD002670.

Rodwell, M. J., and B. J. Hoskins, 2001: Subtropical anticyclones and summer monsoons. J. Climate, 14, 3192-3211, https://doi.org/ 10.1175/1520-0442(2001)014<3192:SAASM >2.0.CO;2.

Si, D., and Y. Ding, 2016: Oceanic forcings of the interdecadal variability in East Asian summer rainfall. J. Climate, 29, 76337649, https://doi.org/10.1175/JCLI-D-15-0792.1.

Sun, X., R. J. Greatbatch, W. Park, and M. Latif, 2010: Two major modes of variability of the East Asian summer monsoon. Quart. J. Roy. Meteor. Soc., 136, 829-841, https://doi.org/10.1002/qj.635.

Sutton, R. T., and D. L. R. Hodson, 2005: Atlantic Ocean forcing of North American and European summer climate. Science, 309, 115-118, https://doi.org/10.1126/science.1109496.

__ and _ 2007: Climate response to basin-scale warming and cooling of the North Atlantic Ocean. J. Climate, 20, 891-907, https://doi.org/10.1175/JCLI4038.1.

Takaya, K., and H. Nakamura, 2001: A formulation of a phaseindependent wave-activity flux for stationary and migratory quasigeostrophic eddies on a zonally varying basic flow. J. Atmos. Sci., 58, 608-627, https://doi.org/10.1175/1520-0469 (2001)058<0608:AFOAPI $>2.0 . \mathrm{CO} ; 2$.

Thoma, M., R. J. Greatbatch, C. Kadow, and R. Gerdes, 2015: Decadal hindcasts initialized using observed surface wind stress: Evaluation and prediction out to 2024. Geophys. Res. Lett., 42, 6454-6461, https://doi.org/10.1002/2015GL064833.

Titchner, H. A., and N. A. Rayner, 2014: The Met Office Hadley Centre sea ice and sea surface temperature data set, version 2: 1 . Sea ice concentrations. J. Geophys. Res. Atmos., 119, 2864 2889, https://doi.org/10.1002/2013JD020316.

Tokinaga, H., S.-P. Xie, and H. Mukougawa, 2017: Early 20thcentury Arctic warming intensified by Pacific and Atlantic multidecadal variability. Proc. Natl. Acad. Sci. USA, 114, 6227-6232, https://doi.org/10.1073/pnas.1615880114.

Wang, H., 2001: The weakening of the Asian monsoon circulation after the end of 1970's. Adv. Atmos. Sci., 18, 376-386, https:// doi.org/10.1007/BF02919316.

_ , and V. M. Mehta, 2008: Decadal variability of the IndoPacific warm pool and its association with atmospheric and oceanic variability in the NCEP-NCAR and SODA reanalyses. J. Climate, 21, 5545-5565, https://doi.org/10.1175/ 2008JCLI2049.1.

Wang, L., P. Xu, W. Chen, and Y. Liu, 2017: Interdecadal variations of the Silk Road pattern. J. Climate, 30, 9915-9932, https://doi.org/10.1175/JCLI-D-17-0340.1.

Wang, Y., S. Li, and D. Luo, 2009: Seasonal response of Asian monsoonal climate to the Atlantic multidecadal oscillation. J. Geophys. Res., 114, D02112, https://doi.org/10.1029/ 2008JD010929.

Wu, B., J. Lin, and T. Zhou, 2016a: Interdecadal circumglobal teleconnection pattern during boreal summer. Atmos. Sci. Lett., 17, 446-452, https://doi.org/10.1002/asl.677.
, T. Zhou, and T. Li, 2016b: Impacts of the PacificJapan and circumglobal teleconnection patterns on the interdecadal variability of the East Asian summer monsoon. J. Climate, 29, 3253-3271, https://doi.org/10.1175/ JCLI-D-15-0105.1.

Wu, R., Z. Wen, S. Yang, and Y. Li, 2010: An interdecadal change in southern China summer rainfall around 1992/ 93. J. Climate, 23, 2389-2403, https://doi.org/10.1175/ 2009JCLI3336.1.

Wyatt, M. G., S. Kravtsov, and A. A. Tsonis, 2012: Atlantic multidecadal oscillation and Northern Hemisphere's climate variability. Climate Dyn., 38, 929-949, https://doi.org/10.1007/ s00382-011-1071-8.

Xie, S.-P., Y. Du, G. Huang, X.-T. Zheng, H. Tokinaga, K. Hu, and Q. Liu, 2010: Decadal shift in El Niño influences on Indowestern Pacific and East Asian climate in the 1970s. J. Climate, 23, 3352-3368, https://doi.org/10.1175/2010JCLI3429.1.

_- Y. Kosaka, Y. Du, K. Hu, J. S. Chowdary, and G. Huang, 2016: Indo-western Pacific ocean capacitor and coherent climate anomalies in post-ENSO summer: A review. Adv. Atmos. Sci., 33, 411-432, https://doi.org/10.1007/s00376-015-5192-6.

Yang, F., and K.-M. Lau, 2004: Trend and variability of China precipitation in spring and summer: Linkage to sea-surface temperatures. Int. J. Climatol., 24, 1625-1644, https://doi.org/ 10.1002/joc.1094.

Yang, J., Q. Liu, S.-P. Xie, Z. Liu, and L. Wu, 2007: Impact of the Indian Ocean SST basin mode on the Asian summer monsoon. Geophys. Res. Lett., 34, L02708, https://doi.org/10.1029/ 2006GL028571.

Yang, X. Q., Q. Xie, Y. M. Zhu, X. G. Sun, and Y. J. Guo, 2005: Decadal-to-interdecadal variability of precipitation in north China and associated atmospheric and oceanic anomaly patterns (in Chinese). Chin. J. Geophys., 48, 789-797.

Ye, X., W. Zhang, and M. Luo, 2016: The North Pacific Gyre Oscillation and East Asian summer precipitation. Atmos. Sci. Lett., 17, 531-537, https://doi.org/10.1002/asl.688.

Yu, L., T. Furevik, O. H. Otterå, and Y. Gao, 2015: Modulation of the Pacific decadal oscillation on the summer precipitation over east China: A comparison of observations to 600-years control run of Bergen climate model. Climate Dyn., 44, 475494, https://doi.org/10.1007/s00382-014-2141-5.

Zhang, H., Z. Wen, R. Wu, Z. Chen, and Y. Guo, 2017: Interdecadal changes in the East Asian summer monsoon and associations with sea surface temperature anomaly in the south Indian Ocean. Climate Dyn., 48, 1125-1139, https://doi.org/ 10.1007/s00382-016-3131-6.

Zhang, Y., J. M. Wallace, and D. S. Battisti, 1997: ENSOlike interdecadal variability: 1900-93. J. Climate, 10, 10041020, https://doi.org/10.1175/1520-0442(1997)010<1004: ELIV $>2.0 . \mathrm{CO} ; 2$.

Zhou, T., and Coauthors, 2009: Why the western Pacific subtropical high has extended westward since the late 1970s. J. Climate, 22, 2199-2215, https://doi.org/10.1175/2008JCLI2527.1.

Zhu, Y. L., H. Wang, W. Zhou, and J. Ma, 2011: Recent changes in the summer precipitation pattern in east China and the background circulation. Climate Dyn., 36, 1463-1473, https:// doi.org/10.1007/s00382-010-0852-9.

, _ - J. Ma, T. Wang, and J. Sun, 2015: Contribution of the phase transition of Pacific decadal oscillation to the late 1990s' shift in east China summer rainfall. J. Geophys. Res. Atmos., 120, 8817-8827, https://doi.org/10.1002/2015JD023545.

, T. Wang, and J. Ma, 2016: Influence of internal decadal variability on the summer rainfall in eastern China as simulated 
by CCSM4. Adv. Atmos. Sci., 33, 706-714, https://doi.org/ 10.1007/s00376-016-5269-x.

Zhu, Y. M., and X. Q. Yang, 2003a: Joint propagating patterns of SST and SLP anomalies in the North Pacific on bidecadal and pentadecadal timescales. Adv. Atmos. Sci., 20, 694-710, https://doi.org/10.1007/BF02915396.

, and _ 2003b: Relationships between Pacific decadal oscillation (PDO) and climate variabilities in China (in Chinese). Acta Meteor. Sin., 61, 641-654.
Q. Xie, and Y. Yu, 2008: Covarying modes of the Pacific SST and Northern Hemispheric midlatitude atmospheric circulation anomalies during winter. Prog. Nat. Sci., 18, 1261-1270, https://doi.org/10.1016/ j.pnsc.2008.05.005.

Zhu, Z., T. Li, and J. He, 2014: Out-of-phase relationship between boreal spring and summer decadal rainfall changes in southern China. J. Climate, 27, 1083-1099, https://doi.org/10.1175/ JCLI-D-13-00180.1. 